\title{
Coupled and Tripled Coincidence Point Results with Application to Fredholm Integral Equations
}

\author{
Marwan Amin Kutbi, ${ }^{1}$ Nawab Hussain, ${ }^{1}$ Jamal Rezaei Roshan, ${ }^{2}$ and Vahid Parvaneh ${ }^{3}$ \\ ${ }^{1}$ Department of Mathematics, King AbdulAziz University, P.O. Box 80203, Jeddah 21589, Saudi Arabia \\ ${ }^{2}$ Department of Mathematics, Qaemshahr Branch, Islamic Azad University, Qaemshahr, Iran \\ ${ }^{3}$ Department of Mathematics, Gilan-E-Gharb Branch, Islamic Azad University, Gilan-E-Gharb, Iran
}

Correspondence should be addressed to Vahid Parvaneh; zam.dalahoo@gmail.com

Received 25 January 2014; Accepted 29 March 2014; Published 18 May 2014

Academic Editor: Ljubomir B. Ćirić

Copyright (C) 2014 Marwan Amin Kutbi et al. This is an open access article distributed under the Creative Commons Attribution License, which permits unrestricted use, distribution, and reproduction in any medium, provided the original work is properly cited.

\begin{abstract}
The aim of this paper is to define weak $\alpha-\psi-\varphi$-contractive mappings and to establish coupled and tripled coincidence point theorems for such mappings defined on $G_{b}$-metric spaces using the concept of rectangular $G$ - $\alpha$-admissibility. As an application, we derive new coupled and tripled coincidence point results for weak $\psi$ - $\varphi$-contractive mappings in partially ordered $G_{b}$-metric spaces. Our results are generalizations and extensions of some recent results in the literature. We also present an example as well as an application to nonlinear Fredholm integral equations in order to illustrate the effectiveness of our results.
\end{abstract}

\section{Introduction and Mathematical Preliminaries}

The concept of generalized metric space, or a G-metric space, was introduced by Mustafa and Sims.

Definition 1 (G-metric space [1]). Let $X$ be a nonempty set and let $G: X \times X \times X \rightarrow R^{+}$be a function satisfying the following properties:

(G1) $G(x, y, z)=0$ if and only if $x=y=z$;

(G2) $0<G(x, x, y)$, for all $x, y \in X$ with $x \neq y$;

(G3) $G(x, x, y) \leq G(x, y, z)$, for all $x, y, z \in X$ with $y \neq z$;

(G4) $G(x, y, z)=G(x, z, y)=G(y, z, x)=\cdots$ (symmetry in all three variables);

(G5) $G(x, y, z) \leq G(x, a, a)+G(a, y, z)$, for all $x, y, z, a \in X$ (rectangle inequality).

Then, the function $G$ is called a $G$-metric on $X$ and the pair $(X, G)$ is called a $G$-metric space.

Recently, Aghajani et al. in [2] motivated by the concept of $b$-metric [3] introduced the concept of generalized $b$-metric spaces ( $G_{b}$-metric spaces) and then they presented some basic properties of $G_{b}$-metric spaces.

The following is their definition of $G_{b}$-metric spaces.

Definition 2 (see [2]). Let $X$ be a nonempty set and let $s \geq 1$ be a given real number. Suppose that a mapping $G: X \times X \times X \rightarrow$ $\mathbb{R}^{+}$satisfies the following:

$\left(G_{b} 1\right) G(x, y, z)=0$ if $x=y=z$,

$\left(G_{b} 2\right) 0<G(x, x, y)$ for all $x, y \in X$ with $x \neq y$,

$\left(G_{b} 3\right) G(x, x, y) \leq G(x, y, z)$ for all $x, y, z \in X$ with $y \neq z$,

$\left(G_{b} 4\right) G(x, y, z)=G(p\{x, y, z\})$, where $p$ is a permutation of $x, y, z$ (symmetry),

$\left(G_{b} 5\right) G(x, y, z) \leq s[G(x, a, a)+G(a, y, z)]$ for all $x, y, z, a \in$ $X$ (rectangle inequality).

Then $G$ is called a generalized $b$-metric and the pair $(X, G)$ is called a generalized $b$-metric space or a $G_{b}$-metric space.

Each $G$-metric space is a $G_{b}$-metric space with $s=1$.

Example 3 (see [2]). Let $(X, G)$ be a $G$-metric space and $G_{*}(x, y, z)=G(x, y, z)^{p}$, where $p>1$ is a real number. Then $G_{*}$ is a $G_{b}$-metric with $s=2^{p-1}$. 
Example 4 (see [4]). Let $X=\mathbb{R}$ and $d(x, y)=|x-y|^{2}$. We know that $(X, d)$ is a $b$-metric space with $s=2$. Let $G(x, y, z)=d(x, y)+d(y, z)+d(z, x)$, it is easy to see that $(X, G)$ is not a $G_{b}$-metric space. Indeed, $\left(G_{b} 3\right)$ is not true for $x=0, y=2$, and $z=1$. However, $G(x, y, z)=$ $\max \{d(x, y), d(y, z), d(z, x)\}$ is a $G_{b}$-metric on $\mathbb{R}$ with $s=2$.

Definition 5 (see [2]). A $G_{b}$-metric $G$ is said to be symmetric if $G(x, y, y)=G(y, x, x)$, for all $x, y \in X$.

Proposition 6 (see [2]). Let $X$ be a $G_{b}$-metric space. Then for each $x, y, z, a \in X$ it follows that

(1) if $G(x, y, z)=0$, then $x=y=z$,

(2) $G(x, y, z) \leq s(G(x, x, y)+G(x, x, z))$,

(3) $G(x, y, y) \leq 2 s G(y, x, x)$,

(4) $G(x, y, z) \leq s(G(x, a, z)+G(a, y, z))$.

Definition 7 (see [2]). Let $X$ be a $G_{b}$-metric space. One defines $d_{G}(x, y)=G(x, y, y)+G(x, x, y)$, for all $x, y \in X$. It is easy to see that $d_{G}$ defines a $b$-metric $d$ on $X$, which one calls the $b$-metric associated with $G$.

Definition 8 (see [2]). Let $X$ be a $G_{b}$-metric space. A sequence $\left\{x_{n}\right\}$ in $X$ is said to be

(1) $G_{b}$-Cauchy if, for each $\varepsilon>0$, there exists a positive integer $n_{0}$ such that, for all $m, n, l \geq n_{0}, G\left(x_{n}, x_{m}, x_{l}\right)<$ $\mathcal{\varepsilon}$;

(2) $G_{b}$-convergent to a point $x \in X$ if, for each $\varepsilon>0$, there exists a positive integer $n_{0}$ such that, for all $m, n \geq n_{0}$, $G\left(x_{n}, x_{m}, x\right)<\varepsilon$.

Proposition 9 (see [2]). Let $X$ be $a G_{b}$-metric space. Then the following are equivalent:

(1) the sequence $\left\{x_{n}\right\}$ is $G_{b}$-Cauchy,

(2) for any $\varepsilon>0$ there exists $n_{0} \in \mathbb{N}$ such that $G\left(x_{n}, x_{m}\right.$, $\left.x_{m}\right)<\varepsilon$ for all $m, n \geq n_{0}$.

Proposition 10 (see [2]). Let $X$ be $a G_{b}$-metric space. The following are equivalent.

(1) $\left\{x_{n}\right\}$ is $G_{b}$-convergent to $x$.

(2) $G\left(x_{n}, x_{n}, x\right) \rightarrow 0$, as $n \rightarrow+\infty$.

(3) $G\left(x_{n}, x, x\right) \rightarrow 0$, as $n \rightarrow+\infty$.

Definition 11 (see [2]). A $G_{b}$-metric space $X$ is called $G_{b^{-}}$ complete if every $G_{b}$-Cauchy sequence is $G_{b}$-convergent in $X$.

Proposition 12. Let $(X, G)$ and $\left(X^{\prime}, G^{\prime}\right)$ be two $G_{b}$-metric spaces. Then a function $f: X \rightarrow X^{\prime}$ is $G_{b}$-continuous at a point $x \in X$ if and only if it is $G_{b}$-sequentially continuous at $x$; that is, whenever $\left\{x_{n}\right\}$ is $G_{b}$-convergent to $x,\left\{f\left(x_{n}\right)\right\}$ is $G_{b^{-}}^{\prime}$ convergent to $f(x)$.

Proposition 13. Let $(X, G)$ be a $G_{b}$-metric space. A mapping $F: X \times X \rightarrow X$ is said to be continuous if, for any two
$G_{b}$-convergent sequences $\left\{x_{n}\right\}$ and $\left\{y_{n}\right\}$ converging to $x$ and $y$, respectively, $\left\{F\left(x_{n}, y_{n}\right)\right\}$ is $G_{b}$-convergent to $F(x, y)$.

In general, a $G_{b}$-metric function $G(x, y, z)$ for $s>1$ is not jointly continuous in all its variables. The following is an example of a discontinuous $G_{b}$-metric.

Example 14 (see [4]). Let $X=\mathbb{N} \cup\{\infty\}$ and let $D: X \times X \rightarrow \mathbb{R}$ be defined by

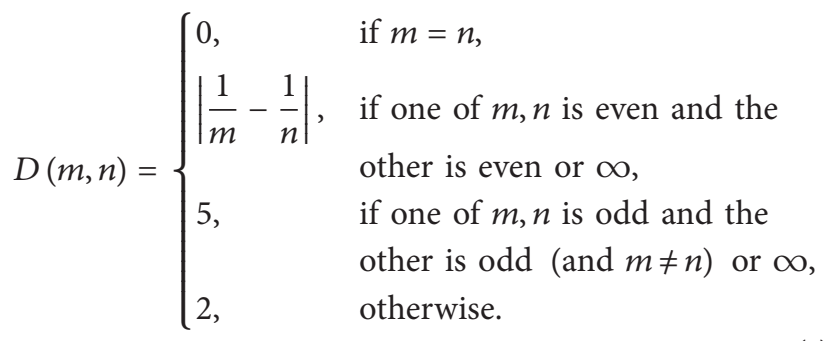

Then it is easy to see that, for all $m, n, p \in X$, we have

$$
D(m, p) \leq \frac{5}{2}(D(m, n)+D(n, p)) .
$$

Thus, $(X, D)$ is a $b$-metric space with $s=5 / 2$ (see [5]).

Let $G(x, y, z)=\max \{D(x, y), D(y, z), D(z, x)\}$. It is easy to see that $G$ is a $G_{b}$-metric with $s=5 / 2$ which is not a continuous function.

We will need the following simple lemma about the $G_{b}$ convergent sequences in the proof of our main results.

Lemma 15 (see [4]). Let $(X, G)$ be a $G_{b}$-metric space with $s>$ 1 and suppose that $\left\{x_{n}\right\},\left\{y_{n}\right\}$, and $\left\{z_{n}\right\}$ are $G_{b}$-convergent to $x$, $y$, and $z$, respectively. Then one has

$$
\begin{aligned}
\frac{1}{s^{3}} G(x, y, z) & \leq \liminf _{n \rightarrow \infty} G\left(x_{n}, y_{n}, z_{n}\right) \\
& \leq \limsup _{n \rightarrow \infty} G\left(x_{n}, y_{n}, z_{n}\right) \\
& \leq s^{3} G(x, y, z) .
\end{aligned}
$$

In particular, if $x=y=z$, then we have $\lim _{n \rightarrow \infty} G\left(x_{n}, y_{n}\right.$ ,$\left.z_{n}\right)=0$.

The existence of fixed points, coupled fixed points, and tripled fixed points for contractive type mappings in partially ordered metric spaces has been considered recently by several authors (see [6-28], etc.)

Lakshmikantham and Ćirić [17] introduced the notions of mixed $g$-monotone mapping and coupled coincidence point and proved some coupled coincidence point and common coupled fixed point theorems in partially ordered complete metric spaces.

Definition 16 (see [17]). Let $(X, \preceq)$ be a partially ordered set and let $F: X \times X \rightarrow X$ and $g: X \rightarrow X$ be two mappings. $F$ has the mixed $g$-monotone property, if $F$ is monotone 
$g$-nondecreasing in its first argument and is monotone $g$ nonincreasing in its second argument; that is, for all $x_{1}, x_{2} \in$ $X, g x_{1} \preceq g x_{2}$ implies $F\left(x_{1}, y\right) \preceq F\left(x_{2}, y\right)$ for any $y \in X$ and for all $y_{1}, y_{2} \in X, g y_{1} \preceq g y_{2}$ implies $F\left(x, y_{1}\right) \succeq F\left(x, y_{2}\right)$ for any $x \in X$.

Definition 17 (see $[7,17])$. An element $(x, y) \in X \times X$ is called

(1) a coupled fixed point of mapping $F: X \times X \rightarrow X$ if $x=F(x, y)$ and $y=F(y, x)$,

(2) a coupled coincidence point of mappings $F: X \times X \rightarrow$ $X$ and $g: X \rightarrow X$ if $g(x)=F(x, y)$ and $g(y)=$ $F(y, x)$,

(3) a common coupled fixed point of mappings $F: X \times$ $X \rightarrow X$ and $g: X \rightarrow X$ if $x=g(x)=F(x, y)$ and $y=g(y)=F(y, x)$.

Definition 18 (see [17]). Let $X$ be a nonempty set. We say that the mappings $F: X \times X \rightarrow X$ and $g: X \rightarrow X$ are commutative if $g(F(x, y))=F(g x, g y)$ for all $x, y \in X$.

Choudhury and Maity [10] have established some coupled fixed point results for mappings with mixed monotone property in partially ordered $G$-metric spaces. They obtained the following results.

Theorem 19 (see [10, Theorem 3.1]). Let $(X, \preceq)$ be a partially ordered set and let $G$ be a $G$-metric on $X$ such that $(X, G)$ is a complete G-metric space. Let $F: X \times X \rightarrow X$ be a continuous mapping having the mixed monotone property on $X$. Assume that there exists $k \in[0,1)$ such that

$$
G(F(x, y), F(u, v), F(w, z)) \leq \frac{k}{2}[G(x, u, w)+G(y, v, z)]
$$

for all $x \preceq u \preceq w$ and $y \geq v \geq z$, where either $u \neq w$ or $v \neq z$.

If there exist $x_{0}, y_{0} \in X$ such that $x_{0} \preceq F\left(x_{0}, y_{0}\right)$ and $y_{0} \succeq$ $F\left(y_{0}, x_{0}\right)$, then $F$ has a coupled fixed point in $X$; that is, there exist $x, y \in X$ such that $x=F(x, y)$ and $y=F(y, x)$.

Theorem 20 (see [10, Theorem 3.2]). If, in the above theorem, in place of the continuity of $F$, one assumes the following conditions, namely,

(i) if a nondecreasing sequence $\left\{x_{n}\right\} \rightarrow x$, then $x_{n} \preceq x$ for all $n$,

(ii) if a nonincreasing sequence $\left\{y_{n}\right\} \rightarrow y$, then $y_{n} \geq y$ for all $n$,

then $F$ has a coupled fixed point.

Definition 21 (see [29]). Let $(X, \preceq)$ be a partially ordered set and let $G$ be a $G$-metric on $X$. One says that $(X, G, \preceq)$ is regular if the following conditions hold.

(i) If $\left\{x_{n}\right\}$ is a nondecreasing sequence with $x_{n} \rightarrow x$, then $x_{n} \preceq x$ for all $n \in \mathbb{N}$.

(ii) If $\left\{x_{n}\right\}$ is a nonincreasing sequence with $x_{n} \rightarrow x$, then $x_{n} \geq x$ for all $n \in \mathbb{N}$.
Definition 22 (see [10]). Let $(\mathscr{X}, G)$ be a generalized $b$-metric space. Mappings $f: \mathscr{X}^{2} \rightarrow \mathscr{X}$ and $g: \mathscr{X} \rightarrow \mathscr{X}$ are called compatible if

$$
\begin{aligned}
& \lim _{n \rightarrow \infty} G\left(g f\left(x_{n}, y_{n}\right), f\left(g x_{n}, g y_{n}\right), f\left(g x_{n}, g y_{n}\right)\right)=0, \\
& \lim _{n \rightarrow \infty} G\left(g f\left(y_{n}, x_{n}\right), f\left(g y_{n}, g x_{n}\right), f\left(g y_{n}, g x_{n}\right)\right)=0
\end{aligned}
$$

hold whenever $\left\{x_{n}\right\}$ and $\left\{y_{n}\right\}$ are sequences in $\mathscr{X}$ such that

$$
\begin{aligned}
& \lim _{n \rightarrow \infty} f\left(x_{n}, y_{n}\right)=\lim _{n \rightarrow \infty} g x_{n}, \\
& \lim _{n \rightarrow \infty} f\left(y_{n}, x_{n}\right)=\lim _{n \rightarrow \infty} g y_{n} .
\end{aligned}
$$

On the other hand, Berinde and Borcut [25] introduced the concept of tripled fixed point and obtained some tripled fixed point theorems for contractive type mappings in partially ordered metric spaces. For a survey of tripled fixed point theorems and related topics we refer the reader to [25-28, 30].

Definition 23 (see $[25,26])$. Let $(\mathscr{X}, \preceq)$ be a partially ordered set, $f: \mathscr{X}^{3} \rightarrow \mathscr{X}$, and $g: \mathscr{X} \rightarrow \mathscr{X}$.

(1) An element $(x, y, z) \in \mathscr{X}^{3}$ is called a tripled fixed point of $f$ if $f(x, y, z)=x, f(y, x, y)=y$, and $f(z, y, x)=z$.

(2) An element $(x, y, z) \in \mathscr{X}^{3}$ is called a tripled coincidence point of the mappings $f$ and $g$ if $f(x, y, z)=$ $g x, f(y, x, y)=g y$, and $f(z, y, x)=g z$.

(3) An element $(x, y, z) \in \mathscr{X}^{3}$ is called a tripled common fixed point of $f$ and $g$ if $x=g(x)=f(x, y, z), y=$ $g(y)=f(y, x, y)$, and $z=g(z)=f(z, y, x)$.

(4) One says that $f$ has the mixed $g$-monotone property if $f(x, y, z)$ is $g$-nondecreasing in $x, g$-nonincreasing in $y$, and $g$-nondecreasing in $z$; that is, if, for any $x, y, z \in \mathscr{X}$,

$$
\begin{array}{ll}
x_{1}, x_{2} \in \mathscr{X}, & g x_{1} \preceq g x_{2} \Longrightarrow f\left(x_{1}, y, z\right) \preceq f\left(x_{2}, y, z\right), \\
y_{1}, y_{2} \in \mathscr{X}, & g y_{1} \preceq g y_{2} \Longrightarrow f\left(x, y_{1}, z\right) \succeq f\left(x, y_{2}, z\right), \\
z_{1}, z_{2} \in \mathscr{X}, & g z_{1} \preceq g z_{2} \Longrightarrow f\left(x, y, z_{1}\right) \preceq f\left(x, y, z_{2}\right) .
\end{array}
$$

Definition 24 (see [28]). Let $\mathscr{X}$ be a nonempty set. One says that the mappings $f: \mathscr{X}^{3} \rightarrow \mathscr{X}$ and $g: X \rightarrow X$ commute if $g(f(x, y, z))=f(g x, g y, g z)$, for all $x, y, z \in \mathscr{X}$.

In [26], Borcut obtained the following.

Theorem 25 (see [26, Corollary 1]). Let $(\mathscr{X}, \preceq)$ be a partially ordered set and suppose there is a metric $d$ on $\mathscr{X}$ such that $(\mathscr{X}, d)$ is a complete metric space. Let $f: \mathscr{X}^{3} \rightarrow \mathscr{X}$ and $g: X \rightarrow \mathscr{X}$ be such that $f$ has the $g$-mixed monotone property. Assume that there exists $k \in[0,1)$ such that

$$
\begin{aligned}
& d(f(x, y, z), f(u, v, w)) \\
& \quad \leq k \max \{d(g x, g u), d(g y, g v), d(g z, g w)\}
\end{aligned}
$$


for all $x, y, z, u, v, w \in \mathscr{X}$ with $g x \preceq g u, g y \geq g v$, and $g z \preceq g w$. Suppose $f\left(\mathscr{X}^{3}\right) \subseteq g(\mathscr{X})$ and $g$ is continuous and commutes with $f$ and also suppose either

(a) $f$ is continuous, or

(b) $\mathscr{X}$ has the following properties:

(i) if a nondecreasing sequence $x_{n} \rightarrow x$, then $x_{n} \preceq$ $x$ for all $n$,

(ii) if a nonincreasing sequence $y_{n} \rightarrow y$, then $y_{n} \geq y$ for all $n$.

If there exist $x_{0}, y_{0}, z_{0} \in \mathscr{X}$ such that $g x_{0} \preceq f\left(x_{0}, y_{0}, z_{0}\right)$, $g y_{0} \succeq f\left(y_{0}, x_{0}, z_{0}\right)$, and $g z_{0} \preceq f\left(z_{0}, y_{0}, x_{0}\right)$, then $f$ and $g$ have a tripled coincidence point.

Definition 26. Let $(\mathscr{X}, G)$ be a generalized $b$-metric space. Mappings $f: \mathscr{X}^{3} \rightarrow \mathscr{X}$ and $g: X \rightarrow X$ are called compatible if

$$
\begin{gathered}
\lim _{n \rightarrow \infty} G\left(g f\left(x_{n}, y_{n}, z_{n}\right), f\left(g x_{n}, g y_{n}, g z_{n}\right),\right. \\
\left.f\left(g x_{n}, g y_{n}, g z_{n}\right)\right)=0, \\
\lim _{n \rightarrow \infty} G\left(g f\left(y_{n}, x_{n}, y_{n}\right), f\left(g y_{n}, g x_{n}, g y_{n}\right),\right. \\
\left.f\left(g y_{n}, g x_{n}, g y_{n}\right)\right)=0, \\
\lim _{n \rightarrow \infty} G\left(g f\left(z_{n}, y_{n}, x_{n}\right), f\left(g z_{n}, g y_{n}, g x_{n}\right),\right. \\
\left.f\left(g z_{n}, g y_{n}, g x_{n}\right)\right)=0
\end{gathered}
$$

hold whenever $\left\{x_{n}\right\},\left\{y_{n}\right\}$, and $\left\{z_{n}\right\}$ are sequences in $\mathscr{X}$ such that

$$
\begin{aligned}
& \lim _{n \rightarrow \infty} f\left(x_{n}, y_{n}, z_{n}\right)=\lim _{n \rightarrow \infty} g x_{n}, \\
& \lim _{n \rightarrow \infty} f\left(y_{n}, x_{n}, y_{n}\right)=\lim _{n \rightarrow \infty} g y_{n}, \\
& \lim _{n \rightarrow \infty} f\left(z_{n}, y_{n}, x_{n}\right)=\lim _{n \rightarrow \infty} g z_{n} .
\end{aligned}
$$

Let $\psi:[0,+\infty) \rightarrow[0,+\infty)$ satisfies the following:

(i) $\psi$ is continuous and nondecreasing,

(ii) $\psi(t)=0$ if and only if $t=0$.

That is, $\psi$ is an altering distance function.

In this paper, we obtain some coupled and tripled coincidence point theorems for nonlinear $(\psi, \varphi)$ weakly contractive mappings which are $G$ - $\alpha$-admissible with respect to another function in partially ordered $G_{b}$-metric spaces. These results generalize and modify several comparable results in the literature.

\section{Main Results}

Samet et al. [31] defined the notion of $\alpha$-admissible mapping as follows.
Definition 27. Let $T$ be a self-mapping on $X$ and let $\alpha$ : $X \times X \rightarrow[0,+\infty)$ be a function. One says that $T$ is an $\alpha-$ admissible mapping if

$$
x, y \in X, \quad \alpha(x, y) \geq 1 \Longrightarrow \alpha(T x, T y) \geq 1 .
$$

Definition 28 (see [32]). Let $(X, G)$ be a $G$-metric space, let $T$ be a self-mapping on $X$, and let $\alpha: X^{3} \rightarrow[0,+\infty)$ be a function. One says that $T$ is an $G$ - $\alpha$-admissible mapping if

$$
x, y, z \in X, \quad \alpha(x, y, z) \geq 1 \Longrightarrow \alpha(T x, T y, T z) \geq 1 .
$$

Following the recent work in [33-35] we present the following definition in the setting of $G$-metric spaces.

Definition 29. Let $(X, G)$ be a $G$-metric space and let $f, g$ : $X \rightarrow X$ and $\alpha: X^{3} \rightarrow[0,+\infty)$. One says that $f$ is a rectangular $G$ - $\alpha$-admissible mapping with respect to $g$ if

(R1) $\alpha(g x, g y, g z) \geq 1$ implies $\alpha(f x, f y, f z) \geq 1, x, y, z \in$ $X$,

(R2) $\{\alpha(g x, g y, g y) \geq 1, \alpha(g y, g z, g z) \geq 1\}$ implies $\alpha(g x, g z, g z) \geq 1, x, y, z \in X$.

Lemma 30. Let $f$ be a rectangular $G$ - $\alpha$-admissible mapping with respect to $g$ such that $f(X) \subseteq g(X)$. Assume that there exists $x_{0} \in X$ such that $\alpha\left(g x_{0}, f x_{0}, f x_{0}\right) \geq 1$. Define sequence $\left\{y_{n}\right\}$ by $y_{n}=g x_{n}=f x_{n-1}$. Then

$$
\alpha\left(y_{n}, y_{m}, y_{m}\right) \geq 1 \quad \forall n, m \in \mathbb{N} \text { with } n<m .
$$

Now, we prove the following coincidence point result.

Theorem 31. Let $(X, G)$ be a generalized $b$-metric space and let $f, g: X \rightarrow X$ satisfy the following condition:

$$
\begin{aligned}
& \alpha(g x, g y, g z) \psi(s G(f x, f y, f z)) \\
& \quad \leq \psi(G(g x, g y, g z))-\varphi(G(g x, g y, g z))
\end{aligned}
$$

for all $x, y, z \in \mathcal{X}$, where $\psi, \varphi:[0, \infty) \rightarrow[0, \infty)$ are two altering distance mappings, $\alpha: X^{3} \rightarrow[0,+\infty)$, and $f$ is a rectangular $G$ - $\alpha$-admissible mapping with respect to $g$.

Then, maps $f$ and $g$ have a coincidence point if

(i) $f(X) \subseteq g(X)$,

(ii) there exists $x_{0} \in X$ such that $\alpha\left(g x_{0}, f x_{0}, f x_{0}\right) \geq 1$,

(iii) $f$ and $g$ are continuous and compatible and $(X, G)$ is complete,

(iii') one of $f(X)$ or $g(X)$ is complete and assume that whenever $\left\{x_{n}\right\}$ in $X$ is a sequence such that $\alpha\left(x_{n}, x_{n+1}, x_{n+1}\right) \geq 1$ for all $n \in \mathbb{N} \cup\{0\}$ and $x_{n} \rightarrow x$ as $n \rightarrow+\infty$, we have $\alpha\left(x_{n}, x, x\right) \geq 1$ for all $n \in \mathbb{N} \cup\{0\}$.

Proof. Let $x_{0} \in X$ be such that $\alpha\left(g x_{0}, f x_{0}, f x_{0}\right) \geq 1$. According to (i) one can define the sequence $\left\{y_{n}\right\}$ as $y_{n+1}=$ $g x_{n+1}=f x_{n}$ for all $n=0,1,2, \ldots$.

As $\alpha\left(g x_{0}, g x_{1}, g x_{1}\right)=\alpha\left(g x_{0}, f x_{0}, f x_{0}\right) \geq 1$ and since $f$ is an $G$ - $\alpha$-admissible mapping with respect to $g$, then 
$\alpha\left(y_{1}, y_{2}, y_{2}\right)=\alpha\left(f x_{0}, f x_{1}, f x_{1}\right) \geq 1$. Continuing this process, we get $\alpha\left(y_{n}, y_{n+1}, y_{n+1}\right) \geq 1$ for all $n \in \mathbb{N} \cup\{0\}$.

If $y_{n}=y_{n+1}$, then $x_{n}$ is a coincidence point of $f$ and $g$.

Now, assume that $y_{n} \neq y_{n+1}$ for all $n$; that is,

$$
G\left(y_{n}, y_{n+1}, y_{n+2}\right)>0 \text {, }
$$

for all $n$. Let $G_{n}=G\left(y_{n}, y_{n+1}, y_{n+2}\right)$. Then, from (14) we obtain that

$$
\begin{aligned}
\psi( & \left.s G\left(y_{n+1}, y_{n+2}, y_{n+3}\right)\right) \\
& \leq \alpha\left(y_{n}, y_{n+1}, y_{n+2}\right) \psi\left(s G\left(y_{n+1}, y_{n+2}, y_{n+3}\right)\right) \\
& =\alpha\left(g x_{n}, g x_{n+1}, g x_{n+2}\right) \psi\left(s G\left(f x_{n}, f x_{n+1}, f x_{n+2}\right)\right) \\
& \leq \psi\left(G\left(y_{n}, y_{n+1}, y_{n+2}\right)\right)-\varphi\left(G\left(y_{n}, y_{n+1}, y_{n+2}\right)\right) .
\end{aligned}
$$

We prove that $G_{n+1} \leq G_{n}$ for each $n \in \mathbb{N}$. If $G_{n+1}>G_{n}$ for some $n \in \mathbb{N}$, then from (16) we have $\psi\left(G_{n+1}\right) \leq \psi\left(G_{n+1}\right)$ $\varphi\left(G_{n}\right)$ which implies that $G_{n}=0$, a contradiction to (15).

Hence, we have $0<G_{n+1} \leq G_{n}$ for each $n \in \mathbb{N}$. Thus, the sequence $\left\{G_{n}\right\}$ is nonincreasing and so there exists $r \geq 0$ such that $\lim _{n \rightarrow \infty} G_{n}=r \geq 0$.

Suppose that $r>0$. Then from (16), taking the limit as $n \rightarrow \infty$ implies that

$$
\psi(r) \leq \psi(r)-\varphi(r)
$$

a contradiction. Hence,

$$
\lim _{n \rightarrow \infty} G_{n}=\lim _{n \rightarrow \infty} G\left(y_{n}, y_{n+1}, y_{n+2}\right)=0 .
$$

Since $y_{n+1} \neq y_{n+2}$ for every $n$, so by property $\left(G_{b} 3\right)$ we obtain

$$
G\left(y_{n}, y_{n+1}, y_{n+1}\right) \leq G\left(y_{n}, y_{n+1}, y_{n+2}\right) .
$$

Hence,

$$
\lim _{n \rightarrow \infty} G\left(y_{n}, y_{n+1}, y_{n+1}\right)=0 .
$$

Also, by part (3) of Proposition 6 we have

$$
\lim _{n \rightarrow \infty} G\left(y_{n}, y_{n}, y_{n+1}\right)=0 .
$$

Now, we prove that $\left\{y_{n}\right\}$ is a $G_{b}$-Cauchy sequence. Assume on contrary that $\left\{y_{n}\right\}$ is not a $G_{b}$-Cauchy sequence. Then there exists $\varepsilon>0$ for which we can find subsequences $\left\{y_{m_{k}}\right\}$ and $\left\{y_{n_{k}}\right\}$ of $\left\{y_{n}\right\}$ such that $m_{k}$ is the smallest index for which $m_{k}>$ $n_{k}>k$ and

$$
G\left(y_{n_{k}}, y_{m_{k}}, y_{m_{k}}\right) \geq \varepsilon
$$

This means that

$$
G\left(x_{n_{k}}, x_{m_{k}-1}, x_{m_{k}-1}\right)<\varepsilon
$$

Since $f$ is a rectangular $G$ - $\alpha$-admissible mapping with respect to $g$, then from Lemma $30 \alpha\left(y_{n_{k}}, y_{m_{k}-1}, y_{m_{\mathrm{k}}-1}\right) \geq 1$. Now, from (14) we have

$$
\begin{aligned}
& \psi\left(s G\left(y_{n_{k}+1}, y_{m_{k}}, y_{m_{k}}\right)\right) \\
& \leq \alpha\left(y_{n_{k}}, y_{m_{k}-1}, y_{m_{k}-1}\right) \psi\left(s G\left(y_{n_{k}+1}, y_{m_{k}}, y_{m_{k}}\right)\right) \\
& =\alpha\left(g x_{n_{k}}, g x_{m_{k}-1}, g x_{m_{k}-1}\right) \psi\left(s G\left(f x_{n_{k}}, f x_{m_{k}-1}, f x_{m_{k}-1}\right)\right) \\
& \leq \psi\left(G\left(y_{n_{k}}, y_{m_{k}-1}, y_{m_{k}-1}\right)\right)-\varphi\left(G\left(y_{n_{k}}, y_{m_{k}-1}, y_{m_{k}-1}\right)\right) .
\end{aligned}
$$

Using $\left(G_{b} 5\right)$ we obtain that

$$
\begin{aligned}
& G\left(y_{n_{k}}, y_{m_{k}}, y_{m_{k}}\right) \\
& \quad \leq s G\left(y_{n_{k}}, y_{n_{k}+1}, y_{n_{k}+1}\right)+s G\left(y_{n_{k}+1}, y_{m_{k}}, y_{m_{k}}\right) .
\end{aligned}
$$

Taking the upper limit as $k \rightarrow \infty$ and using (20) and (23) we obtain that

$$
\limsup _{k \rightarrow \infty}\left(y_{n_{k}+1}, y_{m_{k}}, y_{m_{k}}\right) \geq \frac{\varepsilon}{s} .
$$

Using $\left(G_{b} 5\right)$ we obtain that

$$
\begin{aligned}
& G\left(y_{n_{k}}, y_{m_{k}}, y_{m_{k}}\right) \\
& \quad \leq s G\left(y_{n_{k}}, y_{m_{k}-1}, y_{m_{k}-1}\right)+s G\left(y_{m_{k}-1}, y_{m_{k}}, y_{m_{k}}\right) .
\end{aligned}
$$

Taking the upper limit as $k \rightarrow \infty$ and using (20) and (23) we obtain that

$$
\liminf _{k \rightarrow \infty} G\left(y_{n_{k}}, y_{m_{k}-1}, y_{m_{k}-1}\right) \geq \frac{\varepsilon}{s} .
$$

Taking the upper limit as $k \rightarrow \infty$ in (24) and using (23) and (26) we obtain that

$$
\begin{aligned}
\psi(\epsilon) \leq & \psi\left(\operatorname{slimsup}_{k \rightarrow \infty} G\left(y_{n_{k}+1}, y_{m_{k}}, y_{m_{k}}\right)\right) \\
\leq & \psi\left(\limsup _{k \rightarrow \infty} G\left(y_{n_{k}}, y_{m_{k}-1}, y_{m_{k}-1}\right)\right) \\
& -\liminf _{k \rightarrow \infty} \varphi\left(G\left(y_{n_{k}}, y_{m_{k}-1}, y_{m_{k}-1}\right)\right) \\
\leq & \psi(\epsilon)-\varphi\left(\liminf _{k \rightarrow \infty} G\left(y_{n_{k}}, y_{m_{k}-1}, y_{m_{k}-1}\right)\right)
\end{aligned}
$$

which implies that

$$
\varphi\left(\lim _{k \rightarrow \infty} \inf G\left(y_{n_{k}}, y_{m_{k}-1}, y_{m_{k}-1}\right)\right)=0,
$$

so $\lim _{k \rightarrow \infty} \inf G\left(y_{n_{k}}, y_{m_{k}-1}, y_{m_{k}-1}\right)=0$, a contradiction to (28). It follows that $\left\{y_{n}\right\}$ is a $G_{b}$-Cauchy sequence in $X$.

Suppose first that (iii) holds. Then there exists

$$
\lim _{n \rightarrow \infty} f x_{n}=\lim _{n \rightarrow \infty} g x_{n}=z \in \mathscr{X} .
$$


Further, since $f$ and $g$ are continuous and compatible, we get that

$$
\begin{gathered}
\lim _{n \rightarrow \infty} f g x_{n}=f z, \quad \lim _{n \rightarrow \infty} g f x_{n}=g z, \\
\lim _{n \rightarrow \infty} G\left(f g x_{n}, f g x_{n}, g f x_{n}\right)=0 .
\end{gathered}
$$

We will show that $f z=g z$. Indeed, we have

$$
\begin{aligned}
G(f z, g z, g z) \leq & s\left[G\left(f z, f g x_{n}, f g x_{n}\right)+G\left(f g x_{n}, g z, g z\right)\right] \\
\leq & s G\left(f z, f g x_{n}, f g x_{n}\right) \\
& +s^{2}\left[G\left(f g x_{n}, g f x_{n}, g f x_{n}\right)\right. \\
& \left.\quad+G\left(g f x_{n}, g z, g z\right)\right] \\
\longrightarrow & s \cdot 0+s^{2} \cdot 0+s^{2} \cdot 0=0 \text { as }(n \rightarrow \infty),
\end{aligned}
$$

and it follows that $f z=g z$. It means that $f$ and $g$ have a coincidence point. then

In the case ( $\mathrm{iii}^{\prime}$ ), if we assume that $g(X)$ is $G_{b}$-complete,

$$
\lim _{n \rightarrow \infty} f x_{n}=\lim _{n \rightarrow \infty} g x_{n}=g u=z
$$

for some $u \in \mathscr{X}$. Also, from (iii') we have $\alpha\left(g x_{n}, g u, g u\right) \geq 1$. Applying (14) with $x=x_{n}$ and $y=u$, we have

$$
\begin{aligned}
& \psi\left(G\left(f x_{n}, f u, f u\right)\right) \\
& \quad \leq \alpha\left(g x_{n}, g u, g u\right) \psi\left(s G\left(f x_{n}, f u, f u\right)\right) \\
& \quad \leq \psi\left(G\left(g x_{n}, g u, g u\right)\right)-\varphi\left(G\left(g x_{n}, g u, g u\right)\right) .
\end{aligned}
$$

It follows that $G\left(f x_{n}, f u, f u\right) \rightarrow 0$ when $n \rightarrow \infty$; that is, $f x_{n} \rightarrow f u$. Uniqueness of the limit yields that $f u=z=g u$. Hence, $f$ and $g$ have a coincidence point $u \in X$.

Theorem 32. Let $(X, G, \preceq)$ be an ordered generalized b-metric space and let $f, g: X \rightarrow X$ satisfy the following condition:

$$
\begin{aligned}
& \psi(s G(f x, f y, f z)) \\
& \quad \leq \psi(G(g x, g y, g z))-\varphi(G(g x, g y, g z))
\end{aligned}
$$

for all $x, y, z \in X$, with $g x \preceq g y \preceq g z$, where $\psi, \varphi:[0, \infty) \rightarrow$ $[0, \infty)$ are two altering distance functions.

Then, maps $f$ and $g$ have a coincidence point if

(i) $f$ is g-nondecreasing with respect to $\preceq$ and $f(X) \subseteq$ $g(X)$;

(ii) there exists $x_{0} \in X$ such that $g x_{0} \preceq f x_{0}$;

(iii) $f$ and $g$ are continuous and compatible and $(X, G)$ is complete, or

(iii' $\left.^{\prime}\right)(X, G, \preceq)$ is regular and one of $f(X)$ or $g(X)$ is complete.
Proof. Define $\alpha: X \times X \times X \rightarrow[0,+\infty)$ by

$$
\alpha(x, y, z)= \begin{cases}1, & \text { if } x \preceq y \preceq z \\ 0, & \text { otherwise. }\end{cases}
$$

First, we prove that $f$ is a rectangular $G$ - $\alpha$-admissible mapping with respect to $g$. Assume that $\alpha(g x, g y, g z) \geq$ 1. Therefore, we have $g x \preceq g y \preceq g z$. Since $f$ is $g$ nondecreasing with respect to $\preceq$, we get $f x \preceq f y \preceq f z$; that is, $\alpha(f x, f y, f z) \geq 1$. Also, let $\alpha(x, z, z) \geq 1$ and $\alpha(z, y, y) \geq 1$, and then $x \preceq z$ and $z \preceq y$. Consequently, we deduce that $x \preceq y \preceq y$; that is, $\alpha(x, y, y) \geq 1$. Thus, $f$ is a rectangular $G$ - $\alpha$-admissible mapping with respect to $g$. Since

$$
\begin{aligned}
& \psi(s G(f x, f y, f z)) \\
& \quad \leq \psi(G(g x, g y, g z))-\varphi(G(g x, g y, g z))
\end{aligned}
$$

for all $x, y, z \in X$, with $g x \preceq g y \preceq g z$, then

$$
\begin{aligned}
& \alpha(g x, g y, g z) \psi(s G(f x, f y, f z)) \\
& \quad \leq \psi(G(g x, g y, g z))-\varphi(G(g x, g y, g z)) .
\end{aligned}
$$

Moreover, from (ii) there exists $x_{0} \in X$ such that $g x_{0} \preceq$ $f x_{0} \preceq f x_{0}$; that is, $\alpha\left(g x_{0}, f x_{0}, f x_{0}\right) \geq 1$. Hence, all the conditions of Theorem 31 are satisfied and therefore $f$ and $g$ have a coincidence point.

If $\alpha(x, y, z)=1$ for all $x, y, z \in X$ in Theorem 31 , then we obtain the following coincidence point result.

Theorem 33. Let $(X, G)$ be a generalized $b$-metric space and let $f, g: X \rightarrow X$ satisfy the following condition:

$$
\begin{aligned}
& \psi(s G(f x, f y, f z)) \\
& \quad \leq \psi(G(g x, g y, g z))-\varphi(G(g x, g y, g z))
\end{aligned}
$$

for all $x, y, z \in \mathscr{X}$, where $\psi, \varphi:[0, \infty) \rightarrow[0, \infty)$ are two altering distance functions.

Then, maps $f$ and $g$ have a coincidence point if

(i) $f(X) \subseteq g(X)$,

(ii) $f$ and $g$ are continuous and compatible and $(X, G)$ is complete, or

(ii') one of $f(X)$ or $g(X)$ is complete.

\section{Coupled Fixed Point Results}

We will use the following simple lemma in proving our next results. A similar case in the context of $b$-metric spaces can be found in [24].

Lemma 34. Let $(\mathscr{X}, G)$ be a generalized b-metric space (with the parameter s) and let $f: \mathscr{X}^{2} \rightarrow \mathscr{X}$ and $g: X \rightarrow X$. Suppose that $F: \mathscr{X}^{2} \rightarrow \mathscr{X}^{2}$ is given by

$$
F X=(f(x, y), f(y, x)), \quad X=(x, y) \in X^{2}
$$


and $H: \mathscr{X}^{2} \rightarrow \mathscr{X}^{2}$ is defined by

$$
H X=(g x, g y), \quad X=(x, y) \in \mathscr{X}^{2} .
$$

(a) If a mapping $\Omega_{2}^{m}: \mathscr{X}^{2} \times \mathscr{X}^{2} \times \mathscr{X}^{2} \rightarrow \mathbb{R}^{+}$is given by $\Omega_{2}^{m}(X, U, A)=\max \{G(x, u, a), G(y, v, b)\}$, $X=(x, y), \quad U=(u, v), \quad A=(a, b) \in \mathscr{X}^{2}$,

then $\left(\mathscr{X}^{2}, \Omega_{2}^{m}\right)$ is a generalized b-metric space (with the same parameter $s)$. The space $\left(\mathscr{X}^{2}, \Omega_{2}^{m}\right)$ is $G_{b}$-complete if and only if $(\mathscr{X}, G)$ is $G_{b}$-complete.

(b) If $f$ is continuous from $\left(\mathscr{X}^{2}, \Omega_{2}^{m}\right)$ to $(\mathscr{X}, G)$, then $F$ is continuous in $\left(\mathscr{X}^{2}, \Omega_{2}^{m}\right)$.

(c) If $f$ and $g$ are compatible, then $F$ and $H$ are compatible.

(d) The mapping $f: X^{2} \rightarrow X$ is $G$ - $\alpha$-admissible with respect to $g$; that is,

$$
\begin{gathered}
x, y, u, v, a, b \in X, \\
\alpha((g x, g y),(g u, g v),(g a, g b)) \geq 1 \\
\Longrightarrow \alpha(f(x, y), f(y, x)), \\
(f(u, v), f(v, u)), \\
((f(a, b), f(b, a))) \geq 1
\end{gathered}
$$

if and only if the mapping $F: \mathscr{X}^{2} \rightarrow \mathscr{X}^{2}$ is $G-\alpha-$ admissible with respect to $H$; that is,

$$
\begin{aligned}
& X, U, A \in X^{2}, \\
& \alpha(H X, H U, H A) \geq 1 \\
& \Longrightarrow \alpha(F X, F U, F A) \geq 1,
\end{aligned}
$$

where $\alpha: X^{2} \times X^{2} \times X^{2} \rightarrow[0, \infty)$ is a function.

(e) The statement (d) holds if we replace the G- $\alpha$ admissibility by rectangular $G$ - $\alpha$-admissibility.

Let $(\mathscr{X}, G)$ be a generalized $b$-metric space, $f: \mathscr{X}^{2} \rightarrow \mathscr{X}$, and $g: \mathscr{X} \rightarrow \mathscr{X}$. In the rest of this paper unless otherwise stated, for all $x, y, u, v, z, w \in \mathscr{X}$, let

$$
\begin{aligned}
& N_{f}^{m}(x, y, u, v, z, w) \\
& =\max \{G(f(x, y), f(u, v), f(z, w)), \\
& \quad G(f(y, x), f(v, u), f(w, z))\}, \\
& N_{g}^{m}(x, y, u, v, z, w) \\
& =\max \{G(g x, g u, g z), G(g y, g v, g w)\} .
\end{aligned}
$$

Now, we have the following coupled coincidence point result.
Theorem 35. Let $(\mathscr{X}, G)$ be a generalized b-metric space with the parameter $s$ and let $f: \mathscr{X}^{2} \rightarrow \mathscr{X}$ and $g: \mathscr{X} \rightarrow \mathscr{X}$. Assume that

$$
\begin{aligned}
& \alpha((g x, g y),(g u, g v),(g z, g w)) \\
& \quad \times \psi\left(s N_{f}^{m}(x, y, u, v, z, w)\right) \\
& \quad \leq \psi\left(N_{g}^{m}(x, y, u, v, z, w)\right)-\varphi\left(N_{g}^{m}(x, y, u, v, z, w)\right),
\end{aligned}
$$

for all $x, y, u, v, z, w \in \mathscr{X}$, where $\psi, \varphi:[0, \infty) \rightarrow[0, \infty)$ are altering distance functions, $\alpha:\left(X^{2}\right)^{3} \rightarrow[0, \infty)$, and $f$ is a rectangular $G$ - $\alpha$-admissible mapping with respect to $g$.

Assume also that

(1) $f\left(\mathscr{X}^{2}\right) \subseteq g(\mathscr{X})$;

(2) there exist $x_{0}, y_{0} \in \mathscr{X}$ such that

$$
\begin{gathered}
\alpha\left(\left(g x_{0}, g y_{0}\right),\left(f\left(x_{0}, y_{0}\right), f\left(y_{0}, x_{0}\right)\right),\right. \\
\left.f\left(x_{0}, y_{0}\right), f\left(y_{0}, x_{0}\right)\right) \geq 1, \\
\alpha\left(\left(g y_{0}, g x_{0}\right),\left(f\left(y_{0}, x_{0}\right), f\left(x_{0}, y_{0}\right)\right),\right. \\
\left.f\left(y_{0}, x_{0}\right), f\left(x_{0}, y_{0}\right)\right) \geq 1 .
\end{gathered}
$$

Also, suppose that either

(a) $f$ and $g$ are continuous, the pair $(f, g)$ is compatible, and $(\mathscr{X}, G)$ is $G_{b}$-complete, or

(b) $(g(\mathscr{X}), G)$ is $G_{b}$-complete and assume that whenever $\left\{x_{n}\right\}$ and $\left\{y_{n}\right\}$ in $X$ are sequences such that

$$
\begin{aligned}
& \alpha\left(\left(x_{n}, y_{n}\right),\left(x_{n+1}, y_{n+1}\right),\left(x_{n+1}, y_{n+1}\right)\right) \geq 1, \\
& \alpha\left(\left(y_{n}, x_{n}\right),\left(y_{n+1}, x_{n+1}\right),\left(y_{n+1}, x_{n+1}\right)\right) \geq 1
\end{aligned}
$$

for all $n \in \mathbb{N} \cup\{0\}$ and $x_{n} \rightarrow x, y_{n} \rightarrow y$ as $n \rightarrow+\infty$, we have

$$
\begin{aligned}
& \alpha\left(\left(x_{n}, y_{n}\right),(x, y),(x, y)\right) \geq 1, \\
& \alpha\left(\left(y_{n}, x_{n}\right),(y, x),(y, x)\right) \geq 1
\end{aligned}
$$

for all $n \in \mathbb{N} \cup\{0\}$.

Then, $f$ and $g$ have a coupled coincidence point in $X$.

Proof. Let $\Omega_{2}^{m}$ be the generalized $b$-metric on $\mathscr{X}^{2}$ defined in Lemma 34. Also, define the mappings $F, H: X^{2} \rightarrow \mathscr{X}^{2}$ by $F X=(f(x, y), f(y, x))$ and $H X=(g x, g y), X=(x, y)$ as in Lemma 34. Then, $\left(\mathscr{X}^{2}, \Omega_{2}^{m}\right)$ is a generalized $b$-metric space (with the same parameter $s$ as $\mathscr{X}$ ), such that $F\left(\mathscr{X}^{2}\right) \subseteq H\left(\mathscr{X}^{2}\right)$. Moreover, the contractive condition (47) implies that

$$
\begin{aligned}
& \alpha(H X, H U, H A) \psi\left(s \Omega_{2}^{m}(F X, F U, F A)\right) \\
& \quad \leq \psi\left(\Omega_{2}^{m}(H X, H U, H A)\right)-\varphi\left(\Omega_{2}^{m}(H X, H U, H A)\right)
\end{aligned}
$$

holds for all $X, U, A \in \mathscr{X}^{2}$. Also, one can show that all conditions of Theorem 31 are satisfied for $F$ and $H$ and we 
have proved in Theorem 31 that, under these conditions, it follows that $F$ and $H$ have a coincidence point $\bar{X}=(\bar{x}, \bar{y}) \epsilon$ $\mathscr{X}^{2}$ which is obviously a coupled coincidence point of $f$ and g.

In the following theorem, we give a sufficient condition for the uniqueness of the common coupled fixed point (see also [23]).

Theorem 36. In addition to the hypotheses of Theorem 35, suppose that $f$ and $g$ are commutative and that, for all $(x, y)$ and $\left(x^{*}, y^{*}\right) \in x^{2}$, there exists $(u, v) \in \mathscr{X}^{2}$, such that $\alpha((g x, g y),(g u, g v),(g u, g v)) \geq 1$ and $\alpha\left(\left(g x^{*}\right.\right.$, $\left.\left.g y^{*}\right),(g u, g v),(g u, g v)\right) \geq 1$. Then, $f$ and $g$ have a unique common coupled fixed point of the form $(a, a)$.

Proof. We will use the notations as in the proof of Theorem 35. It was proved in this theorem that the set of coupled coincidence points of $f$ and $g$; that is, the set of coincidence points of $F$ and $H$ in $\mathscr{X}^{2}$ is nonempty. We will show that if $X$ and $X^{*}$ are coincidence points of $F$ and $H$, that is,

$$
H X=F X, \quad H X^{*}=F X^{*},
$$

then $H X=H X^{*}$.

Choose an element $U=(u, v) \in \mathscr{X}^{2}$ such that $\alpha((g x, g y),(g u, g v),(g u, g v)) \geq 1$ and $\alpha\left(\left(g x^{*}, g y^{*}\right)\right.$, $(g u, g v),(g u, g v)) \geq 1$. Let $U_{0}=U$ and choose $U_{1} \in \mathscr{X}^{2}$ so that $H U_{1}=F U_{0}$. Then, we can inductively define a sequence $\left\{H U_{n}\right\}$ such that $H U_{n+1}=F U_{n}$.

As $\alpha((g x, g y),(g u, g v),(g u, g v)) \geq 1$ and $f$ is rectangular $G$ - $\alpha$-admissible with respect to $g$, then $\alpha((f(x, y)$, $f(y, x)),(f(u, v), f(v, u)),(f(u, v), f(v, u))) \geq 1$; that is, $\alpha\left(H X, H U_{0}, H U_{0}\right) \geq 1$ yields that

$$
\begin{aligned}
\alpha(F X, F U, F U) & =\alpha\left(F X, F U_{0}, F U_{0}\right) \\
& =\alpha\left(H X, H U_{1}, H U_{1}\right) \\
& \geq 1
\end{aligned}
$$

Therefore, by the mathematical induction, we obtain that $\alpha\left(H X, H U_{n}, H U_{n}\right) \geq 1$, for all $n \geq 0$.

Applying (47), one obtains that

$$
\begin{aligned}
\psi & \left(s \Omega_{2}^{m}\left(F X, H U_{n+1}, H U_{n+1}\right)\right) \\
& \leq \alpha\left(H X, H U_{n}, H U_{n}\right) \psi\left(s \Omega_{2}^{m}\left(F X, F U_{n}, F U_{n}\right)\right) \\
& \leq \psi\left(\Omega_{2}^{m}\left(H X, H U_{n}, H U_{n}\right)\right)-\varphi\left(\Omega_{2}^{m}\left(H X, H U_{n}, H U_{n}\right)\right) \\
& \leq \psi\left(\Omega_{2}^{m}\left(H X, H U_{n}, H U_{n}\right)\right) .
\end{aligned}
$$

From the properties of $\psi$, we deduce that the sequence $\left\{\Omega_{2}^{m}\left(H X, H U_{n}, H U_{n}\right)\right\}$ is nonincreasing. Hence, if we proceed as in Theorem 31, we can show that

$$
\lim _{n \rightarrow \infty} \Omega_{2}^{m}\left(H X, H U_{n}, H U_{n}\right)=0 ;
$$

that is, $\left\{H U_{n}\right\}$ is $G_{b}$-convergent to $H X$.
Similarly, we can show that $\left\{H U_{n}\right\}$ is $G_{b}$-convergent to $H X^{*}$. Since the limit is unique, it follows that $H X=H X^{*}$.

The compatibility of $f$ and $g$ yields that $F$ and $H$ are compatible, and hence $F$ and $H$ are weak compatible. Since $H X=F X$, we have $H H X=H F X=F H X$. Let $H X=A$. Then, $H A=F A$. Thus, $A$ is another coincidence point of $F$ and $H$. Then, $A=H X=H A$. Therefore, $A=(a, b)$ is a coupled common fixed point of $f$ and $g$.

To prove the uniqueness, assume that $P$ is another common fixed point of $F$ and $H$. Then, $P=H P=F P$ and also $H P=H A$. Thus, $P=H P=H A=A$. Hence, the coupled common fixed point is unique. Also, if $(a, b)$ is a common coupled fixed point of $f$ and $g$, then $(b, a)$ is also a common coupled fixed point of $f$ and $g$. Uniqueness of the common coupled fixed point yields that $a=b$.

$$
\begin{aligned}
& \text { Let } \Omega_{2}^{a}: \mathscr{X}^{2} \times \mathscr{X}^{2} \times \mathscr{X}^{2} \rightarrow \mathbb{R}^{+} \text {be given by } \\
& \Omega_{2}^{a}(X, U, A)=\frac{G(x, u, a)+G(y, v, b)}{2}, \\
& X=(x, y), \quad U=(u, v), \quad A=(a, b) \in \mathscr{X}^{2},
\end{aligned}
$$

and then $\left(\mathscr{X}^{2}, \Omega_{2}^{a}\right)$ is a generalized $b$-metric space (with the same parameter $s)$.

Let $(\mathscr{X}, G)$ be a generalized $b$-metric space, $f: \mathscr{X}^{2} \rightarrow \mathscr{X}$, and $g: \mathscr{X} \rightarrow \mathscr{X}$. For all $x, y, u, v, z, w \in \mathscr{X}$, let

$$
\begin{gathered}
N_{f}^{a}(x, y, u, v, z, w) \\
=\frac{G(f(x, y), f(u, v), f(z, w))}{2} \\
\quad+\frac{G(f(y, x), f(v, u), f(w, z))}{2}, \\
N_{g}^{a}(x, y, u, v, z, w)=\frac{G(g x, g u, g z)+G(g y, g v, g w)}{2} .
\end{gathered}
$$

Remark 37. The result of Theorems 35 and 36 holds, if we replace $\Omega_{2}^{m}, N_{f}^{m}$, and $N_{g}^{m}$ by $\Omega_{2}^{a}, N_{f}^{a}$, and $N_{g}^{a}$, respectively.

\section{Coupled Fixed Point Results in Partially Ordered Generalized $b$-Metric Spaces}

We will use the following simple lemma in proving our results.

Lemma 38. Let $\left(\mathscr{X}, G_{b}, \preceq\right)$ be an ordered generalized b-metric space (with the parameter $s$ ) and let $f: \mathscr{X}^{2} \rightarrow \mathscr{X}$ and $g$ : $\mathscr{X} \rightarrow \mathscr{X}$. Let $F: \mathscr{X}^{2} \rightarrow \mathscr{X}^{2}$ be given by

$$
F X=(f(x, y), f(y, x)), \quad X=(x, y) \in \mathscr{X}^{2}
$$

and $H: \mathscr{X}^{2} \rightarrow \mathscr{X}^{2}$ is defined by

$$
H X=(g x, g y), \quad X=(x, y) \in \mathscr{X}^{2} .
$$


(a) If a relation $\sqsubseteq_{2}$ is defined on $\mathscr{X}^{2}$ by

$$
X \sqsubseteq_{2} U \Longleftrightarrow x \preceq u \wedge y \succeq v, \quad X=(x, y), U=(u, v) \in \mathscr{X}^{2},
$$

then $\left(\mathscr{X}^{2}, \Omega_{2}^{m}, \sqsubseteq_{2}\right)$ and $\left(\mathscr{X}^{2}, \Omega_{2}^{a}, \sqsubseteq_{2}\right)$ are ordered generalized $b$ metric spaces (with the same parameter $s$ ).

(b) If the mapping $f$ has the g-mixed monotone property, then the mapping $F: \mathscr{X}^{2} \rightarrow \mathscr{X}^{2}$ is G-nondecreasing with respect to $\sqsubseteq_{2}$; that is,

$$
H X \sqsubseteq_{2} H U \Longrightarrow F X \sqsubseteq_{2} F U .
$$

Theorem 39. Let $\left(\mathscr{X}, G_{b}, \preceq\right)$ be a partially ordered generalized $b$-metric space with the parameter s and let $f: \mathscr{X}^{2} \rightarrow \mathscr{X}$ and $g: X \rightarrow X$. Assume that

$$
\begin{aligned}
& \psi\left(s N_{f}^{m}(x, y, u, v, z, w)\right) \\
& \quad \leq \psi\left(N_{g}^{m}(x, y, u, v, z, w)\right)-\varphi\left(N_{g}^{m}(x, y, u, v, z, w)\right),
\end{aligned}
$$

for all $x, y, u, v, z, w \in \mathscr{X}$ with $g x \preceq g u \preceq g z$ and $g y \geq$ $g v \geq g w$, where $\psi, \varphi:[0, \infty) \rightarrow[0, \infty)$ are altering distance functions.

Assume also that

(1) $f$ has the mixed $g$-monotone property and $f\left(\mathscr{X}^{2}\right) \subseteq$ $g(x)$;

(2) there exist $x_{0}, y_{0} \in \mathscr{X}$ such that $g x_{0} \preceq f\left(x_{0}, y_{0}\right)$ and $g y_{0} \succeq f\left(y_{0}, x_{0}\right)$.

Also, suppose that either

(a) $f$ and $g$ are continuous, the pair $(f, g)$ is compatible, and $(\mathscr{X}, G)$ is $G_{b}$-complete, or

(b) $\left(\mathscr{X}, G_{b}\right)$ is regular and $(g(\mathscr{X}), G)$ is $G_{b}$-complete.

Then, $f$ and $g$ have a coupled coincidence point in $\mathscr{X}$.

Proof. By Lemma 38, $\left(\mathscr{X}^{2}, \Omega_{2}^{m}, \sqsubseteq_{2}\right)$ is an ordered generalized $b$-metric space (with the same parameter $s$ ).

Define $\alpha: X^{2} \times X^{2} \times X^{2} \rightarrow[0,+\infty)$ by

$$
\alpha((x, y),(u, v),(a, b))= \begin{cases}1, & \text { if }(x, y) \sqsubseteq_{2}(u, v) \sqsubseteq_{2}(a, b), \\ 0, & \text { otherwise. }\end{cases}
$$

First, we prove that $F$ is a rectangular $G$ - $\alpha$-admissible mapping with respect to $H$. Hence, we assume that $\alpha(H X$, $H U, H A) \geq 1$, where $X=(x, y), U=(u, v)$, and $A=(a, b)$. Therefore, we have $H X \sqsubseteq_{2} H U \sqsubseteq_{2} H A$. Since $f$ has the mixed $g$-monotone property, then from Lemma 38, the mapping $F: \mathscr{X}^{2} \rightarrow \mathscr{X}^{2}$ is $G$-nondecreasing with respect to $\sqsubseteq_{2}$; that is,

$$
F X \sqsubseteq_{2} F U \sqsubseteq_{2} F A ;
$$

that is, $\alpha(F X, F U, F A) \geq 1$. Also, let $\alpha(X, A, A) \geq 1$ and $\alpha(A, U, U) \geq 1$; then $X \sqsubseteq_{2} A$ and $A \sqsubseteq_{2} U$. Consequently, we deduce that $X \sqsubseteq_{2} U$; that is, $\alpha(X, U, U) \geq 1$. Thus, $F$ is a rectangular $G$ - $\alpha$-admissible mapping with respect to $H$.

From (62) and the definition of $\alpha$ and $\sqsubseteq_{2}$,

$$
\begin{aligned}
\psi & \left(s \Omega_{2}^{m}(F X, F U, F A)\right) \\
& \leq \psi\left(\Omega_{2}^{m}(H X, H U, H A)\right)-\varphi\left(\Omega_{2}^{m}(H X, H U, H A)\right),
\end{aligned}
$$

for all $X, U, A \in X^{2}$ with $H X \sqsubseteq_{2} H U \sqsubseteq_{2} H A$. Moreover, from (2) there exists $\left(x_{0}, y_{0}\right) \in X^{2}$ such that

$$
\begin{aligned}
H\left(x_{0}, y_{0}\right) & =\left(g x_{0}, g y_{0}\right) \sqsubseteq_{2}\left(\left(x_{0}, y_{0}\right), f\left(y_{0}, x_{0}\right)\right) \\
& =F\left(x_{0}, y_{0}\right) .
\end{aligned}
$$

Hence, all the conditions of Theorem 32 are satisfied and so $F$ and $H$ have a coincidence point $\bar{X}=(\bar{x}, \bar{y}) \in \mathscr{X}^{2}$ which is a coupled coincidence point of $f$ and $g$.

In the following theorem, we give a sufficient condition for the uniqueness of the common coupled fixed point (see also $[25,28,30])$.

Theorem 40. In addition to the hypotheses of Theorem 39, suppose that, for all $(x, y)$ and $\left(x^{*}, y^{*}\right) \in \mathscr{X}^{2}$, there exists $(u, v) \in \mathscr{X}^{2}$, such that $(g u, g v)$ is comparable with $(g x, g y)$ and $\left(g x^{*}, g y^{*}\right)$. Then, $f$ and $g$ have a unique common coupled fixed point of the form $(a, a)$.

Proof. It was proved in Theorem 39 that the set of coupled coincidence points of $f$ and $g$, that is, the set of coincidence points of $F$ and $H$ in $\mathscr{X}^{2}$, is nonempty. We will show that if $X$ and $X^{*}$ are coincidence points of $F$ and $H$, that is,

$$
H X=F X, \quad H X^{*}=F X^{*},
$$

then $H X=H X^{*}$. There exists $(u, v) \in X^{2}$, such that $(g u, g v)$ is comparable with $(g x, g y)$ and $\left(g x^{*}, g y^{*}\right)$. Without any loss of generality, we may assume that $(g x, g y) \sqsubseteq_{2}(g u, g v)$ and $\left(g x^{*}, g y^{*}\right) \sqsubseteq_{2}(g u, g v)$. According to the definition of $\alpha$ in the above theorem, $\alpha((g x, g y),(g u, g v),(g u, g v)) \geq 1$ and $\alpha\left(\left(g x^{*}, g y^{*}\right),(g u, g v),(g u, g v)\right) \geq 1$.

Now, following the proof of Theorem 36, one can obtain that $H X=H X^{*}$. The remainder part of proof is analogous to the proof of Theorem 36 and so we omit it.

Remark 41. In Theorem 39, we can replace the contractive condition (62) by the following:

$$
\begin{aligned}
& \alpha((g x, g y),(g u, g v),(g z, g w)) \\
& \quad \times \psi\left(s N_{f}^{a}(x, y, u, v, z, w)\right) \\
& \quad \leq \psi\left(N_{g}^{a}(x, y, u, v, z, w)\right)-\varphi\left(N_{g}^{a}(x, y, u, v, z, w)\right) .
\end{aligned}
$$

Remark 42. Theorem 39 provides conclusions of Theorems 3.1 and 3.2 of [4] for more general pair of compatible maps.

In Theorem 39, if we take $\psi(t)=t$ for all $t \in[0, \infty)$, we obtain the following result. 
Corollary 43. Let $(\mathscr{X}, G, \preceq)$ be a partially ordered $G_{b^{-}}$ complete generalized $b$-metric space with the parameter $s \geq 1$ and let $f: \mathscr{X}^{2} \rightarrow X$. Assume that

$$
\begin{aligned}
& \frac{G(f(x, y), f(u, v), f(z, w))}{2} \\
& +\frac{G(f(y, x), f(v, u), f(w, z))}{2} \\
& \leq \frac{1}{s} \frac{G(g x, g u, g z)+G(g y, g v, g w)}{2} \\
& -\frac{1}{s} \varphi\left(\frac{G(g x, g u, g z)+G(g y, g v, g w)}{2}\right) \text {, }
\end{aligned}
$$

for all $x, y, u, v, z, w \in \mathscr{X}$ with $x \preceq u \preceq z$ and $y \geq v \geq w$, where $\varphi:[0, \infty) \rightarrow[0, \infty)$ is an altering distance function.

Assume also that

(1) $f$ has the mixed g-monotone property and $f\left(\mathscr{X}^{2}\right) \subseteq$ $g(\mathscr{X})$;

(2) there exist $x_{0}, y_{0} \in \mathscr{X}$ such that $g x_{0} \leq f\left(x_{0}, y_{0}\right)$ and $g y_{0} \geq f\left(y_{0}, x_{0}\right)$.

Also, suppose that either

(a) $f$ is continuous, or

(b) $(\mathscr{X}, G)$ is regular.

Then, $f$ and $g$ have a coupled coincidence point in $X$.

In addition, suppose that, for all $(x, y)$ and $\left(x^{*}, y^{*}\right) \in \mathscr{X}^{2}$, there exists $(u, v) \in \mathscr{X}^{2}$, such that $(u, v)$ is comparable with $(x, y)$ and $\left(x^{*}, y^{*}\right)$. Then, $f$ and $g$ have a unique coupled fixed point of the form $(a, a)$.

In Corollary 43, if we take $\varphi(t)=(1-k) t$ for all $t \in[0, \infty)$, where $k \in[0,1)$, we obtain the following extension of the results by Choudhury and Maity (Theorems 19 and 20).

Corollary 44. Let $(X, G, \preceq)$ be a partially ordered $G_{b^{-}}$ complete generalized $b$-metric space with the parameter $s \geq 1$ and let $f: \mathscr{X}^{2} \rightarrow \mathscr{X}$. Assume that

$$
\begin{aligned}
& \frac{G(f(x, y), f(u, v), f(z, w))}{2} \\
& +\frac{G(f(y, x), f(v, u), f(w, z))}{2} \\
& \quad \leq \frac{k}{s} \frac{G(x, u, z)+G(y, v, w)}{2},
\end{aligned}
$$

for all $x, y, u, v, z, w \in \mathscr{X}$ with $x \preceq u \preceq z$ and $y \geq v \succeq w$, or $z \preceq u \preceq x$ and $w \geq v \geq y$, where $k \in[0,1)$.

Assume also that

(1) $f$ has the mixed monotone property;

(2) there exist $x_{0}, y_{0} \in \mathscr{X}$ such that $x_{0} \leq f\left(x_{0}, y_{0}\right)$ and $y_{0} \geq f\left(y_{0}, x_{0}\right)$.

Also, suppose that either (a) $f$ is continuous, or

(b) $(\mathscr{X}, G)$ is regular.

Then, $f$ has a coupled fixed point in $X$.

In addition, suppose that, for all $(x, y)$ and $\left(x^{*}, y^{*}\right) \in \mathscr{X}^{2}$, there exists $(u, v) \in \mathscr{X}^{2}$, such that $(u, v)$ is comparable with $(x, y)$ and $\left(x^{*}, y^{*}\right)$. Then, $f$ has a unique coupled fixed point of the form $(a, a)$.

Now, we present an example to illustrate Theorem 39 and Remark 41.

Example 45. Let $X=\mathbb{R}$ be endowed with the usual ordering and let $G_{b}$-metric $G$ on $X$ be given by $G(x, y, z)=$ $\max \left\{|x-y|^{2},|y-z|^{2},|x-z|^{2}\right\}$, where $s=2$. Define $F: X \times$ $X \rightarrow X$ as

$$
F(x, y)=\frac{x-y}{9}, \quad(x, y) \in X \times X
$$

We define $\psi, \varphi:[0, \infty) \rightarrow[0, \infty)$ by

$$
\psi(t)=\ln (t+1), \quad \varphi(t)=\ln \left(\frac{t+1}{c t+1}\right),
$$

where $c=8 / 81$. Also, $F$ has mixed monotone property and satisfies the condition (68). Indeed, for all $x, y, u, v, a, b \in X$ with $x \leq u \leq a$ and $y \geq v \geq b$, we have

$$
\begin{aligned}
& \psi(2(G(F(x, y), F(u, v), F(a, b)))) \\
& =\ln \left(2 \operatorname { m a x } \left\{\left(\frac{x-y}{9}-\frac{u-v}{9}\right)^{2},\left(\frac{u-v}{9}-\frac{a-b}{9}\right)^{2},\right.\right. \\
& \left.\left.\left(\frac{a-b}{9}-\frac{x-y}{9}\right)^{2}\right\}+1\right) \\
& =\ln \left(2 \operatorname { m a x } \left\{\left(\frac{x-u+v-y}{9}\right)^{2},\left(\frac{u-a+b-v}{9}\right)^{2},\right.\right. \\
& \left.\left.\left(\frac{a-x+y-b}{9}\right)^{2}\right\}+1\right) \\
& =\ln \left(\frac { 2 } { 8 1 } \operatorname { m a x } \left\{(x-u+v-y)^{2},(u-a+b-v)^{2},\right.\right. \\
& \left.\left.(a-x+y-b)^{2}\right\}+1\right) \\
& \leq \ln \left(\frac { 4 } { 8 1 } \operatorname { m a x } \left\{(x-u)^{2}+(v-y)^{2},(u-a)^{2}\right.\right. \\
& \left.\left.+(b-v)^{2},(a-x)^{2}+(y-b)^{2}\right\}+1\right) \\
& \leq \ln \left(\frac { 4 } { 8 1 } \left[\max \left\{(x-u)^{2},(u-a)^{2},(a-x)^{2}\right\}\right.\right. \\
& \left.\left.+\max \left\{(v-y)^{2},(b-v)^{2},(y-b)^{2}\right\}\right]+1\right)
\end{aligned}
$$




$$
\begin{aligned}
= & \ln \left(\frac{8}{81} \frac{G(x, u, a)+G(y, v, b)}{2}+1\right) \\
= & \ln \left(c \frac{G(x, u, a)+G(y, v, b)}{2}+1\right) \\
= & \ln \left(\frac{G(x, u, a)+G(y, v, b)}{2}+1\right) \\
& -\ln \left(\frac{((G(x, u, a)+G(y, v, b)) / 2)+1}{c((G(x, u, a)+G(y, v, b)) / 2)+1}\right) \\
= & \psi\left(\frac{G(x, u, a)+G(y, v, b)}{2}\right) \\
& -\varphi\left(\frac{G(x, u, a)+G(y, v, b)}{2}\right) .
\end{aligned}
$$

Similarly,

$$
\begin{aligned}
\psi(2(G(F(y, x), F(v, u)), F(b, a))) \\
\leq \psi\left(\frac{G(x, u, a)+G(y, v, b)}{2}\right) \\
\quad-\varphi\left(\frac{G(x, u, a)+G(y, v, b)}{2}\right) .
\end{aligned}
$$

So,

$$
\begin{gathered}
\psi\left(2 \left(\frac{G(F(x, y), F(u, v), F(a, b))}{2}\right.\right. \\
\left.\left.\quad+\frac{G(F(y, x), F(v, u), F(b, a))}{2}\right)\right) \\
\leq \psi\left(\frac{G(x, u, a)+G(y, v, b)}{2}\right) \\
-\varphi\left(\frac{G(x, u, a)+G(y, v, b)}{2}\right) .
\end{gathered}
$$

Finally, there are obviously $x_{0}, y_{0} \in X$ such that $x_{0} \leq$ $F\left(x_{0}, y_{0}\right)$ and $y_{0} \geq F\left(y_{0}, x_{0}\right)$. Thus, we conclude that the mapping $F$ has a coupled fixed point (which is $(0,0)$ ).

Consider now the same example, but with the $G$-metric

$$
G(x, y, z)=\max \{|x-y|,|y-z|,|x-z|\}
$$

on $X=\mathbb{R}$. The respective contractive condition

$$
\begin{array}{r}
\psi(G(F(x, y), F(u, v), F(a, b))) \\
\leq \psi\left(\frac{G(x, u, a)+G(y, v, b)}{2}\right) \\
\quad-\varphi\left(\frac{G(x, u, a)+G(y, v, b)}{2}\right)
\end{array}
$$

does not hold for all $x, y, u, v, a, b \in X$ such that $x \geq u \geq a$ and $y \leq v \leq b$. Indeed, for $x=1, y=u=v=a=b=0$ it reduces to

$$
\begin{aligned}
\psi( & G(F(1,0), F(0,0), F(0,0))) \\
= & \psi\left(\frac{1}{9}\right)=0.10536051565 \\
\nless & 0.4054651081-0.35726300629 \\
= & \psi\left(\frac{1}{2}\right)-\varphi\left(\frac{1}{2}\right) \\
= & \psi\left(\frac{G(1,0,0)+G(0,0,0)}{2}\right) \\
& -\varphi\left(\frac{G(1,0,0)+G(0,0,0)}{2}\right) .
\end{aligned}
$$

We conclude that, using a $G_{b}$-metric instead of the standard one, one has more possibilities for choosing a control function in order to get a coupled fixed point result.

Remark 46. Theorems 3.5, 3.6, and 3.7 of [4] are special cases of Theorem 39.

\section{Tripled Coincidence Point Results}

In this section we prove some tripled coincidence and tripled common fixed point results.

Lemma 47. Let $(\mathscr{X}, G, \preceq)$ be an ordered generalized b-metric space (with the parameter $s$ ) and let $f: \mathscr{X}^{3} \rightarrow \mathscr{X}$ and $g$ : $x \rightarrow \mathscr{X}$.

(a) If a relation $\sqsubseteq_{3}$ is defined on $\mathscr{X}^{3}$ by

$$
\begin{aligned}
& X \sqsubseteq_{3} U \Longleftrightarrow x \preceq u \wedge y \succeq v \wedge z \preceq w, \\
& X=(x, y, z), \quad U=(u, v, w) \in \mathscr{X}^{3},
\end{aligned}
$$

and a mapping $\Omega_{3}^{m}: \mathscr{X}^{3} \times \mathscr{X}^{3} \times \mathscr{X}^{3} \rightarrow \mathbb{R}^{+}$is given by

$$
\Omega_{3}^{m}(X, U, A)=\max \{G(x, u, a), G(y, v, b), G(z, w, c)\},
$$

for all $X=(x, y, z), U=(u, v, w)$, and $A=(a, b, c) \in X^{3}$, then $\left(\mathscr{X}^{3}, \Omega_{3}^{m}, \sqsubseteq_{3}\right)$ is an ordered generalized $b$-metric space (with the same parameter $s)$. The space $\left(\mathscr{X}^{3}, \Omega_{3}^{m}\right)$ is $G_{b}$-complete if and only if $(\mathscr{X}, G)$ is $G_{b}$-complete.

(b) If the mapping $f$ has the $g$-mixed monotone property, then the mapping $F: \mathscr{X}^{3} \rightarrow \mathscr{X}^{3}$ given by

$$
\begin{array}{r}
F X=(f(x, y, z), f(y, x, y), f(z, y, x)), \\
X=(x, y, z) \in X^{3}
\end{array}
$$

is $G$-nondecreasing with respect to $\sqsubseteq_{3}$; that is,

$$
H X \sqsubseteq_{3} H U \Longrightarrow F X \sqsubseteq_{3} F U \text {, }
$$

where $H: \mathscr{X}^{3} \rightarrow \mathscr{X}^{3}$ is defined by

$$
H X=(g x, g y, g z), \quad X=(x, y, z) \in \mathscr{X}^{3} .
$$


(c) If $f$ is continuous from $\left(\mathscr{X}^{3}, \Omega_{3}^{m}\right)$ to $(\mathscr{X}, G)$, then $F$ is continuous in $\left(\mathscr{X}^{3}, \Omega_{3}^{m}\right)$.

(d) If $f$ and $g$ are compatible, then $F$ and $H$ are compatible.

(e) The mapping $f: X^{3} \rightarrow X$ is G- $\alpha$-admissible with respect to $g$; that is,

$x, y, z, u, v, w, a, b, c \in X$,

$$
\begin{gathered}
\alpha((g x, g y, g z),(g y, g x, g y),(g z, g y, g x)) \geq 1 \\
\Longrightarrow \alpha((f(x, y, z), f(y, x, y), f(z, y, x)), \\
(f(u, v, w), f(v, u, v), f(w, v, u)), \\
(f(a, b, c), f(b, a, b), f(c, b, a))) \geq 1
\end{gathered}
$$

if and only if the mapping $F: \mathscr{X}^{3} \rightarrow \mathscr{X}^{3}$ is $G$ - $\alpha$-admissible with respect to $H$; that is,

$$
\begin{aligned}
& X, U, A \in X^{3}, \\
& \alpha(H X, H U, H A) \geq 1 \\
& \Longrightarrow \alpha(F X, F U, F A) \geq 1,
\end{aligned}
$$

where $\alpha: X^{3} \times X^{3} \times X^{3} \rightarrow[0, \infty)$ is a function.

Let $(\mathscr{X}, G, \preceq)$ be an ordered generalized $b$-metric space, $f: \mathscr{X}^{3} \rightarrow \mathscr{X}$, and $g: \mathscr{X} \rightarrow \mathscr{X}$. For all $x, y, z, u, v, w, a, b, c \in$ $\mathscr{X}$, let

$$
\begin{gathered}
M_{f}^{m}(x, y, z, u, v, w, a, b, c) \\
=\max \{G(f(x, y, z), f(u, v, w), f(a, b, c)), \\
G(f(y, x, y), f(v, u, v), f(b, a, b)), \\
\quad G(f(z, y, x), f(w, v, u), f(c, b, a))\}, \\
M_{g}^{m}(x, y, z, u, v, w, a, b, c) \\
=\max \{G(g x, g u, g a), G(g y, g v, g b), G(g z, g w, g c)\} .
\end{gathered}
$$

Theorem 48. Let $(\mathscr{X}, G)$ be a generalized b-metric space with the parameter $s$ and let $f: \mathscr{X}^{3} \rightarrow \mathscr{X}$ and $g: \mathscr{X} \rightarrow \mathscr{X}$. Assume that

$$
\begin{gathered}
\alpha((g x, g y, g z),(g u, g v, g w),(g a, g b, g c)) \\
\quad \times \psi\left(s M_{f}^{m}(x, y, z, u, v, w, a, b, c)\right) \\
\leq \psi\left(M_{g}^{m}(x, y, z, u, v, w, a, b, c)\right) \\
-\varphi\left(M_{g}^{m}(x, y, z, u, v, w, a, b, c)\right),
\end{gathered}
$$

for all $x, y, z, u, v, w, a, b, c \in \mathscr{X}$ where $\psi, \varphi:[0, \infty) \rightarrow$ $[0, \infty)$ are altering distance functions and $\alpha:\left(X^{3}\right)^{3} \rightarrow[0, \infty)$ is a mapping such that $f$ is a rectangular $G-\alpha$-admissible mapping with respect to $g$.

Assume also that

(1) $f\left(\mathscr{X}^{3}\right) \subseteq g(\mathscr{X})$;
(2) there exist $x_{0}, y_{0}, z_{0} \in \mathscr{X}$ such that

$$
\begin{aligned}
& \alpha\left(\left(g x_{0}, g y_{0}, g z_{0}\right),\right. \\
& \quad\left(f\left(x_{0}, y_{0}, z_{0}\right), f\left(y_{0}, x_{0}, y_{0}\right), f\left(z_{0}, y_{0}, x_{0}\right)\right), \\
& \left.\quad\left(f\left(x_{0}, y_{0}, z_{0}\right), f\left(y_{0}, x_{0}, y_{0}\right), f\left(z_{0}, y_{0}, x_{0}\right)\right)\right) \geq 1, \\
& \alpha\left(\left(g y_{0}, g x_{0}, g y_{0}\right),\right. \\
& \quad\left(f\left(y_{0}, x_{0}, y_{0}\right), f\left(x_{0}, y_{0}, z_{0}\right), f\left(y_{0}, x_{0}, y_{0}\right)\right), \\
& \left.\quad\left(f\left(y_{0}, x_{0}, y_{0}\right), f\left(x_{0}, y_{0}, z_{0}\right), f\left(y_{0}, x_{0}, y_{0}\right)\right)\right) \geq 1, \\
& \alpha\left(\left(g z_{0}, g y_{0}, g x_{0}\right),\right. \\
& \quad\left(f\left(z_{0}, y_{0}, x_{0}\right), f\left(y_{0}, x_{0}, y_{0}\right), f\left(x_{0}, y_{0}, z_{0}\right)\right), \\
& \left.\quad\left(f\left(z_{0}, y_{0}, x_{0}\right), f\left(y_{0}, x_{0}, y_{0}\right), f\left(x_{0}, y_{0}, z_{0}\right)\right)\right) \geq 1 .
\end{aligned}
$$

\section{Also, suppose that either}

(a) $f$ and $g$ are continuous, the pair $(f, g)$ is compatible, and $(\mathscr{X}, G)$ is $G_{b}$-complete, or

(b) $(g(\mathscr{X}), G)$ is $G_{b}$-complete and assume that whenever $\left\{x_{n}\right\},\left\{y_{n}\right\},\left\{z_{n}\right\}$ in $X$ are sequences such that

$$
\begin{aligned}
& \alpha\left(\left(x_{n}, y_{n}, z_{n}\right),\left(x_{n+1}, y_{n+1}, z_{n+1}\right),\left(x_{n+1}, y_{n+1}, z_{n+1}\right)\right) \geq 1, \\
& \alpha\left(\left(y_{n}, x_{n}, y_{n}\right),\left(y_{n+1}, x_{n+1}, y_{n+1}\right),\left(y_{n+1}, x_{n+1}, y_{n+1}\right)\right) \geq 1, \\
& \alpha\left(\left(z_{n}, y_{n}, x_{n}\right),\left(z_{n+1}, y_{n+1}, x_{n+1}\right),\left(z_{n+1}, y_{n+1}, x_{n+1}\right)\right) \geq 1
\end{aligned}
$$

for all $n \in \mathbb{N} \cup\{0\}$ and $x_{n} \rightarrow x, y_{n} \rightarrow y$, and $z_{n} \rightarrow z$ as $n \rightarrow+\infty$, we have

$$
\begin{aligned}
& \alpha\left(\left(x_{n}, y_{n}, z_{n}\right),(x, y, z),(x, y, z)\right) \geq 1, \\
& \alpha\left(\left(y_{n}, x_{n}, y_{n}\right),(y, x, y),(y, x, y)\right) \geq 1, \\
& \alpha\left(\left(z_{n}, y_{n}, x_{n}\right),(z, y, x),(z, y, x)\right) \geq 1
\end{aligned}
$$

for all $n \in \mathbb{N} \cup\{0\}$.

Then, $f$ and $g$ have a tripled coincidence point in $\mathscr{X}$.

Theorem 49. In addition to the hypotheses of Theorem 48, suppose that $f$ and $g$ are commutative and that, for all $(x, y, z)$ and $\left(x^{*}, y^{*}, z^{*}\right) \in \mathscr{X}^{3}$, there exists $(u, v, w) \in \mathscr{X}^{3}$, such that

$$
\begin{gathered}
\alpha((g x, g y, g z),(g u, g v, g w),(g u, g v, g w)) \geq 1, \\
\alpha\left(\left(g x^{*}, g y^{*}, g z^{*}\right),(g u, g v, g w),(g u, g v, g w)\right) \geq 1 .
\end{gathered}
$$

Then, $f$ and $g$ have a unique common tripled fixed point of the form $(a, a, a)$. 


$$
\begin{aligned}
& \text { Let } \\
& \begin{array}{l}
\Omega_{3}^{a}(X, U, A)=\frac{G(x, u, a)+G(y, v, b)+G(z, w, c)}{3}, \\
X=(x, y, z), \quad U=(u, v, w), \quad A=(a, b, c) \in X^{3}, \\
M_{f}^{a}(x, y, z, u, v, w, a, b, c) \\
=\frac{G(f(x, y, z), f(u, v, w), f(a, b, c))}{3} \\
\quad+\frac{G(f(y, x, y), f(v, u, v), f(b, a, b))}{3} \\
\quad+\frac{G(f(z, y, x), f(w, v, u), f(c, b, a))}{3}, \\
M_{g}^{a}(x, y, z, u, v, w, a, b, c) \\
=\frac{G(g x, g u, g a)+G(g y, g v, g b)+G(g z, g w, g c)}{3} .
\end{array}
\end{aligned}
$$

Remark 50. In Theorem 48, we can replace the contractive condition (87) by the following:

$$
\begin{gathered}
\alpha((g x, g y, g z),(g u, g v, g w),(g a, g b, g c)) \\
\quad \times \psi\left(s M_{f}^{a}(x, y, z, u, v, w, a, b, c)\right) \\
\leq \psi\left(M_{g}^{a}(x, y, z, u, v, w, a, b, c)\right) \\
-\varphi\left(M_{g}^{a}(x, y, z, u, v, w, a, b, c)\right) .
\end{gathered}
$$

The following tripled fixed point results in ordered metric spaces can be obtained.

Theorem 51. Let $(\mathscr{X}, G, \preceq)$ be a partially ordered generalized $b$-metric space with the parameter sand let $f: \mathscr{X}^{3} \rightarrow \mathscr{X}$ and $g: \mathscr{X} \rightarrow \mathscr{X}$. Assume that

$$
\begin{aligned}
\psi( & \left.s M_{f}^{m}(x, y, z, u, v, w, a, b, c)\right) \\
\leq & \psi\left(M_{g}^{m}(x, y, z, u, v, w, a, b, c)\right) \\
& -\varphi\left(M_{g}^{m}(x, y, z, u, v, w, a, b, c)\right),
\end{aligned}
$$

for all $x, y, z, u, v, w, a, b, c \in \mathscr{X}$ with $g x \leq g u \leq g a, g y \geq$ $g v \geq g b$, and $g z \leq g w \leq g c$, where $\psi, \varphi:[0, \infty) \rightarrow[0, \infty)$ are altering distance functions.

Assume also that

(1) $f$ has the mixed g-monotone property and $f\left(\mathscr{X}^{3}\right) \subseteq$ $g(\mathscr{X})$;

(2) there exist $x_{0}, y_{0}, z_{0} \in \mathscr{X}$ such that $g x_{0} \leq f\left(x_{0}, y_{0}, z_{0}\right)$, $g y_{0} \geq f\left(y_{0}, x_{0}, y_{0}\right)$, and $g z_{0} \leq f\left(z_{0}, y_{0}, x_{0}\right)$.

Also, suppose that either

(a) $f$ and $g$ are continuous, the pair $(f, g)$ is compatible, and $(\mathscr{X}, G)$ is $G_{b}$-complete, or (b) $(\mathscr{X}, G)$ is regular and $(g(\mathscr{X}), G)$ is $G_{b}$-complete.

Then, $f$ and $g$ have a tripled coincidence point in $X$.

Theorem 52. In addition to the hypotheses of Theorem 48, suppose that $f$ and $g$ are commutative and that, for all $(x, y, z)$ and $\left(x^{*}, y^{*}, z^{*}\right) \in \mathscr{X}^{3}$, there exists $(u, v, w) \in \mathscr{X}^{3}$, such that $(g u, g v, g w)$ is comparable with $(g x, g y, g z)$ and $\left(g x^{*}, g y^{*}, g z^{*}\right)$. Then, $f$ and $g$ have a unique common tripled fixed point of the form $(a, a, a)$.

Remark 53. In Theorem 51, we can replace the contractive condition (94) by the following:

$$
\begin{aligned}
& \psi\left(s M_{f}^{a}(x, y, z, u, v, w, a, b, c)\right) \\
& \leq \psi\left(M_{g}^{a}(x, y, z, u, v, w, a, b, c)\right) \\
&-\varphi\left(M_{g}^{a}(x, y, z, u, v, w, a, b, c)\right) .
\end{aligned}
$$

Remark 54. Theorem 51 extends Theorem 2.1 of [36] to a compatible pair.

Remark 55. Corollaries 2.2, 2.3, 2.6, 2.7, and 2.8 of [36] are special cases of Theorem 51 .

Remark 56. Theorem 25 is a special case of Theorems 51.

\section{Application to Integral Equations}

As an application of the (coupled) fixed point theorems established in Section 4, we study the existence and uniqueness of a solution to a Fredholm nonlinear integral equation.

In order to compare our results to the ones in $[37,38]$ we will consider the same integral equation; that is,

$$
\begin{aligned}
x(t)= & \int_{a}^{b}\left(K_{1}(t, s)+K_{2}(t, s)\right)(f(s, x(s))+g(s, x(s))) d s \\
& +h(t),
\end{aligned}
$$

where $t \in I=[a, b]$.

Let $\Theta$ denote the set of all functions $\theta:[0, \infty) \rightarrow[0, \infty)$ satisfying the following.

$\left(\mathrm{i}_{\theta}\right) \theta$ is nondecreasing and $(\theta(r))^{p} \leq \theta\left(r^{p}\right)$, for all $p \geq 1$.

$\left(\mathrm{ii}_{\theta}\right)$ There exists $\varphi \in \Phi$ such that $2 \theta(r)=(r / 2)-\varphi(r / 2)$, for all $r \in[0, \infty)$.

$\Theta$ is nonempty, as $\theta_{1}(r)=2 k r$ with $0 \leq 4 k<1$ is an element of $\Theta$.

Like in [38], we assume that the functions $K_{1}, K_{2}, f$, and $g$ fulfill the following conditions.

Assumption 57. Consider the following:

(i) $K_{1}(t, s) \geq 0$ and $K_{2}(t, s) \leq 0$, for all $t, s \in I$; 
(ii) there exist two positive numbers $\lambda$ and $\mu$ and $\theta \in \Theta$ such that, for all $x, y \in \mathbb{R}$ with $x \geq y$, the following Lipschitzian type conditions hold:

$$
\begin{aligned}
& 0 \leq f(t, x)-f(t, y) \leq \lambda \theta(x-y), \\
& -\mu \theta(x-y) \leq g(t, x)-g(t, y) \leq 0 ;
\end{aligned}
$$

(iii)

$$
\begin{aligned}
& \left(\max \left\{\lambda^{p}, \mu^{p}\right\}\right) \\
& \quad \sup _{t \in I}\left[\left(\int_{a}^{b} K_{1}(t, s) d s\right)^{p}+\left(\int_{a}^{b}-K_{2}(t, s) d s\right)^{p}\right] \leq \frac{1}{2^{3 p-3}} .
\end{aligned}
$$

Definition 58 (see [38]). A pair $(\alpha, \beta) \in X^{2}$ with $X=C(I, \mathbb{R})$ is called a coupled lower-upper solution of (96) if, for all $t \in I$,

$$
\begin{aligned}
\alpha(t) \leq & \int_{a}^{b} K_{1}(t, s)[f(s, \alpha(s))+g(s, \beta(s))] d s \\
& +\int_{a}^{b} K_{2}(t, s)[f(s, \beta(s))+g(s, \alpha(s))] d s+h(t), \\
\beta(t) \geq & \int_{a}^{b} K_{1}(t, s)[f(s, \beta(s))+g(s, \alpha(s))] d s \\
& +\int_{a}^{b} K_{2}(t, s)[f(s, \alpha(s))+g(s, \beta(s))] d s+h(t) .
\end{aligned}
$$

Theorem 59. Consider the integral equation (96) with

$$
K_{1}, K_{2} \in C(I \times I, \mathbb{R}), \quad h \in C(I, \mathbb{R}) .
$$

Suppose that there exists a coupled lower-upper solution $(\alpha, \beta)$ of (96) with $\alpha \leq \beta$ and that Assumption 57 is satisfied. Then the integral equation (96) has a unique solution in $C(I, \mathbb{R})$.

Proof. Consider on $X=C(I, \mathbb{R})$ the natural partial order relation; that is, for $x, y \in C(I, \mathbb{R})$,

$$
x \leq y \Longleftrightarrow x(t) \leq y(t), \quad \forall t \in I .
$$

It is well known that $X$ is a complete metric space with respect to the sup metric:

$$
d(x, y)=\sup _{t \in I}|x(t)-y(t)|, \quad x, y \in C(I, \mathbb{R}) .
$$

Now for $p \geq 1$ we define

$$
\begin{aligned}
\rho(x, y) & =d(x, y)^{p}=\left(\sup _{t \in I}|x(t)-y(t)|\right)^{p} \\
& =\sup _{t \in I}|x(t)-y(t)|^{p}, \quad x, y \in C(I, \mathbb{R}) .
\end{aligned}
$$

Define

$$
G(x, y, z)=\max \{\rho(x, y), \rho(y, z), \rho(z, x)\} .
$$

It is easy to see that $(X, G)$ is a complete $G_{b}$-metric space with $s=2^{p-1}$ (see Example 3 ).

Now define on $X^{2}$ the following partial order: for all $(x, y),(u, v) \in X^{2}$

$$
(x, y) \leq(u, v) \Longleftrightarrow x(t) \leq u(t), \quad y(t) \geq v(t) \quad \forall t \in I .
$$

Obviously, for any $(x, y),(z, t) \in X^{2}$, the element (max $\{F(x, y), F(z, t)\}, \min \{F(y, x), F(t, z)\})$ is comparable with $(F(x, y), F(y, x))$ and $(F(z, t), F(t, z))$.

Define now the mapping $F: X \times X \rightarrow X$ by

$$
\begin{aligned}
F(x, y)(t)= & \int_{a}^{b} K_{1}(t, s)[f(s, x(s))+g(s, y(s))] d s \\
& +\int_{a}^{b} K_{2}(t, s)[f(s, y(s))+g(s, x(s))] d s \\
& +h(t), \quad \forall t \in I .
\end{aligned}
$$

It is not difficult to prove, like in [38], that $F$ has the mixed monotone property. Now for $x, y, u, v, a, b \in X$ with $x \geq u \geq$ $a$ and $y \leq v \leq b$, we have

$$
\rho(F(x, y), F(u, v))=\sup _{t \in I}|F(x, y)(t)-F(u, v)(t)|^{p} .
$$

Let us first evaluate the expression in the right hand side. According to the computations done by Berinde in [37],

$$
\begin{aligned}
& F(x, y)(t)-F(u, v)(t) \\
& =\int_{a}^{b} K_{1}(t, s)[f(s, x(s))+g(s, y(s))] d s \\
& +\int_{a}^{b} K_{2}(t, s)[f(s, y(s))+g(s, x(s))] d s \\
& -\int_{a}^{b} K_{1}(t, s)[f(s, u(s))+g(s, v(s))] d s \\
& -\int_{a}^{b} K_{2}(t, s)[f(s, v(s))+g(s, u(s))] d s \\
& =\int_{a}^{b} K_{1}(t, s)[f(s, x(s))-f(s, u(s))+g(s, y(s)) \\
& -g(s, v(s))] d s \\
& +\int_{a}^{b} K_{2}(t, s)[f(s, y(s))-f(s, v(s))+g(s, x(s)) \\
& -g(s, u(s))] d s \\
& =\int_{a}^{b} K_{1}(t, s)[(f(s, x(s))-f(s, u(s))) \\
& -(g(s, v(s))-g(s, y(s)))] d s
\end{aligned}
$$


Abstract and Applied Analysis

15

$$
\begin{gathered}
-\int_{a}^{b} K_{2}(t, s)[(f(s, y(s))-f(s, v(s))) \\
-(g(s, u(s))-g(s, x(s)))] d s \\
\leq \int_{a}^{b} K_{1}(t, s)[\lambda \theta(x(s)-u(s))+\mu \theta(v(s)-y(s))] d s \\
-\int_{a}^{b} K_{2}(t, s)[\lambda \theta(y(s)-v(s))+\mu \theta(u(s)-x(s))] d s .
\end{gathered}
$$

Since the function $\theta$ is nondecreasing and $x \geq u$ and $y \leq v$, we have

$$
\begin{aligned}
& \theta(x(s)-u(s)) \leq \theta\left(\sup _{t \in I}|x(t)-u(t)|\right)=\theta(d(x, u)), \\
& \theta(v(s)-y(s)) \leq \theta\left(\sup _{t \in I}|y(t)-v(t)|\right)=\theta(d(y, v)) .
\end{aligned}
$$

Hence, by (108), in view of the fact that $K_{2}(t, s) \leq 0$, we obtain that

$$
\begin{aligned}
& |F(x, y)(t)-F(u, v)(t)| \\
& \quad \leq \int_{a}^{b} K_{1}(t, s)[\lambda \theta(d(x, u))+\mu \theta(d(y, v))] d s \\
& \quad-\int_{a}^{b} K_{2}(t, s)[\lambda \theta(d(y, v))+\mu \theta(d(x, u))] d s,
\end{aligned}
$$

as all quantities in the right hand side of (108) are nonnegatine.

Now from (108) we have

$$
\begin{aligned}
& |F(x, y)(t)-F(u, v)(t)|^{p} \\
& \leq\left(\int_{a}^{b} K_{1}(t, s)[\lambda \theta(d(x, u))+\mu \theta(d(y, v))] d s\right. \\
& \left.\quad-\int_{a}^{b} K_{2}(t, s)[\lambda \theta(d(v, y))+\mu \theta(d(x, u))] d s\right)^{p} \\
& \leq 2^{p-1}\left(\left(\int_{a}^{b} K_{1}(t, s) d s\right)^{p}(\lambda \theta(d(x, u))+\mu \theta(d(v, y)))^{p}\right. \\
& \quad+\left(-\int_{a}^{b} K_{2}(t, s) d s\right)^{p} \\
& \left.\times(\lambda \theta(d(v, y))+\mu \theta(d(x, u)))^{p}\right)
\end{aligned}
$$

$$
\begin{aligned}
\leq 2^{p-1} & \left(\int_{a}^{b} K_{1}(t, s) d s\right)^{p} \\
& \times 2^{p-1}\left(\lambda^{p} \theta(d(x, u))^{p}+\mu^{p} \theta(d(v, y))^{p}\right) \\
& +\left(-\int_{a}^{b} K_{2}(t, s) d s\right)^{p} \\
& \left.\times 2^{p-1}\left(\lambda^{p} \theta(d(v, y))^{p}+\mu^{p} \theta(d(x, u))^{p}\right)\right) \\
\leq 2^{p-1}( & \left(\int_{a}^{b} K_{1}(t, s) d s\right)^{p} \\
& \times 2^{p-1}\left(\lambda^{p} \theta(\rho(x, u))+\mu^{p} \theta(\rho(v, y))\right) \\
& +\left(-\int_{a}^{b} K_{2}(t, s) d s\right)^{p} \\
& +\left(\mu^{p}\left(\int_{a}^{p-1}\left(\lambda^{p} \theta(\rho(v, y))+\mu^{p} \theta(\rho(x, u))\right)\right)\right. \\
\leq 2^{2 p-2}[ & \left.\left(\lambda^{p}\left(\int_{a}^{b} K_{1}(t, s) d s\right)^{p} K_{2}(t, s) d s\right)^{p}\right) \theta \rho(x, u) \\
& \left.\left.\left.+\int_{a}^{b} K_{2}(t, s) d s\right)^{p}\right) \theta \rho(v, y)\right] .
\end{aligned}
$$

So, we have

$$
\begin{aligned}
\mid F(x, y)(t)- & \left.F(u, v)(t)\right|^{p} \\
\leq 2^{2 p-2}\left[\left(\lambda^{p}\left(\int_{a}^{b} K_{1}(t, s) d s\right)^{p}\right.\right. & \left.+\mu^{p}\left(-\int_{a}^{b} K_{2}(t, s) d s\right)^{p}\right) \theta \rho(x, u) \\
+ & \left(\mu^{p}\left(\int_{a}^{b} K_{1}(t, s) d s\right)^{p}\right. \\
& \left.\left.+\lambda^{p}\left(-\int_{a}^{b} K_{2}(t, s) d s\right)^{p}\right) \theta \rho(y, v)\right] .
\end{aligned}
$$

Similarly, one can obtain that

$$
\begin{aligned}
& |F(u, v)(t)-F(z, t)(t)|^{p} \\
& \quad \leq 2^{2 p-2}\left[\left(\lambda^{p}\left(\int_{a}^{b} K_{1}(t, s) d s\right)^{p}\right.\right.
\end{aligned}
$$




$$
\begin{aligned}
& \left.+\mu^{p}\left(-\int_{a}^{b} K_{2}(t, s) d s\right)^{p}\right) \theta \rho(u, z) \\
+ & \left(\mu^{p}\left(\int_{a}^{b} K_{1}(t, s) d s\right)^{p}\right. \\
+ & \left.\left.\lambda^{p}\left(-\int_{a}^{b} K_{2}(t, s) d s\right)^{p}\right) \theta \rho(v, t)\right], \\
\mid F(z, t)(t)- & \left.F(x, y)(t)\right|^{p} \\
\leq 2^{2 p-2}[ & \left(\lambda^{p}\left(\int_{a}^{b} K_{1}(t, s) d s\right)^{p}\right. \\
+ & \left.\mu^{p}\left(-\int_{a}^{b} K_{2}(t, s) d s\right)^{p}\right) \theta \rho(x, z) \\
+ & \left(\mu^{p}\left(\int_{a}^{b} K_{1}(t, s) d s\right)^{p}\right. \\
& \left.\left.+\lambda^{p}\left(-\int_{a}^{b} K_{2}(t, s) d s\right)^{p}\right) \theta \rho(y, t)\right] .
\end{aligned}
$$

Taking the supremum with respect to $t$ and using (98) we get

$$
\begin{aligned}
& G(F(x, y), F(u, v), F(z, t)) \\
& =\max \left\{\sup _{t \in I}|F(x, y)(t)-F(u, v)(t)|^{p},\right. \\
& \sup _{t \in I}|F(u, v)(t)-F(z, t)(t)|^{p}, \\
& \left.\sup _{t \in I}|F(z, t)(t)-F(x, y)(t)|^{p}\right\} \\
& \leq 2^{2 p-2}\left(\max \left\{\lambda^{p}, \mu^{p}\right\}\right) \\
& \times \sup _{t \in I}\left[\left(\int_{a}^{b} K_{1}(t, s) d s\right)^{p}+\left(\int_{a}^{b}-K_{2}(t, s) d s\right)^{p}\right] \\
& \times \max \{\theta(\rho(x, u))+\theta(\rho(y, v)), \theta(\rho(u, z)) \\
& +\theta(\rho(v, t)), \theta(\rho(x, z))+\theta(\rho(y, t))\} \\
& \leq 2^{2 p-2}\left(\max \left\{\lambda^{p}, \mu^{p}\right\}\right) \\
& \times \sup _{t \in I}\left[\left(\int_{a}^{b} K_{1}(t, s) d s\right)^{p}+\left(\int_{a}^{b}-K_{2}(t, s) d s\right)^{p}\right] \\
& \times \theta(G(x, u, z))+\theta(G(y, v, t)) \\
& \leq \frac{2^{2 p-2}}{2^{3 p-3}}[\theta(G(x, u, z))+\theta(G(y, v, t))] \\
& =\frac{1}{2^{p-1}}[\theta(G(x, u, z))+\theta(G(y, v, t))] .
\end{aligned}
$$

Now, since $\theta$ is nondecreasing, we have

$$
\begin{gathered}
\theta(G(x, u, z)) \leq \theta(G(x, u, z)+G(y, v, t)), \\
\theta(G(y, v, t)) \leq \theta(G(x, u, z)+G(y, v, t))
\end{gathered}
$$

and so

$$
\begin{aligned}
\theta(G(x, u, z))+\theta(G(y, v, t)) \\
\leq 2 \theta(G(x, u, z)+G(y, v, t)) \\
=\frac{G(x, u, z)+G(y, v, t)}{2} \\
\quad-\varphi\left(\frac{G(x, u, z)+G(y, v, t)}{2}\right),
\end{aligned}
$$

by the definition of $\theta$. Finally, from (114) we get that

$$
\begin{aligned}
G(F(x, y), F(u, v), F(z, t)) \\
\leq \quad \frac{1}{2^{p-1}} \frac{G(x, u, z)+G(y, v, t)}{2} \\
\quad-\frac{1}{2^{p-1}} \varphi\left(\frac{G(x, u, z)+G(y, v, t)}{2}\right) .
\end{aligned}
$$

Similarly, we can obtain that

$$
\begin{aligned}
G(F(y, x), F(v, u), F(t, z)) \\
\leq \quad \frac{1}{2^{p-1}} \frac{G(x, u, z)+G(y, v, t)}{2} \\
\quad-\frac{1}{2^{p-1}} \varphi\left(\frac{G(x, u, z)+G(y, v, t)}{2}\right),
\end{aligned}
$$

which is just the contractive condition (69) in Corollary 43.

Now, let $(\alpha, \beta) \in X^{2}$ be a coupled upper-lower solution of (96). Then we have

$$
\alpha(t) \leq F(\alpha, \beta)(t), \quad \beta(t) \geq F(\beta, \alpha)(t),
$$

for all $t \in I$, which show that all hypotheses of Corollary 43 are satisfied.

This proves that $F$ has a coupled fixed point $\left(x_{*}, y_{*}\right)$ in $X^{2}$. is,

Since $\alpha \leq \beta$, by Corollary 43 it follows that $x_{*}=y_{*}$; that

$$
x_{*}=F\left(x_{*}, x_{*}\right)
$$

and therefore $x_{*} \in C(I, \mathbb{R})$ is the solution of the integral equation (96).

\section{Conflict of Interests}

The authors declare that there is no conflict of interests regarding the publications of this paper. 


\section{Authors' Contribution}

All authors contributed equally and significantly in writing this paper. All authors read and approved the final paper.

\section{Acknowledgments}

This paper was funded by the Deanship of Scientific Research (DSR), King Abdulaziz University, Jeddah. Therefore, the first and second authors express their thanks to DSR, KAU for financial support.

\section{References}

[1] Z. Mustafa and B. Sims, "A new approach to generalized metric spaces," Journal of Nonlinear and Convex Analysis, vol. 7, no. 2, pp. 289-297, 2006.

[2] A. Aghajani, M. Abbas, and J. R. Roshan, "Common fixed point of generalized weak contractive mappings in partially ordered $G_{b}$-metric spaces," Filomat. In press.

[3] S. Czerwik, "Contraction mappings in b-metric spaces," Acta Mathematica et Informatica Universitatis Ostraviensis, vol. 1, pp. 5-11, 1993.

[4] Z. Mustafa, J. R. Roshan, and V. Parvaneh, "Coupled coincidence point results for $(\psi, \phi)$-weakly contractive mappings in partially ordered $G_{b}$-metric spaces," Fixed Point Theory and Applications, vol. 2013, article 206, 2013.

[5] N. Hussain, D. Dorić, Z. Kadelburg, and S. Radenović, "Suzukitype fixed point results in metric type spaces," Fixed Point Theory and Applications, vol. 2012, article 126, 2012.

[6] H. Aydi, M. Postolache, and W. Shatanawi, "Coupled fixed point results for $(\psi, \varphi)$-weakly contractive mappings in ordered $G$ metric spaces," Computers \& Mathematics with Applications, vol. 63, no. 1, pp. 298-309, 2012.

[7] T. G. Bhaskar and V. Lakshmikantham, "Fixed point theorems in partially ordered metric spaces and applications," Nonlinear Analysis: Theory, Methods \& Applications, vol. 65, no. 7, pp. 13791393, 2006.

[8] Y. J. Cho, M. H. Shah, and N. Hussain, "Coupled fixed points of weakly F-contractive mappings in topological spaces," Applied Mathematics Letters, vol. 24, no. 7, pp. 1185-1190, 2011.

[9] B. S. Choudhury and A. Kundu, "A coupled coincidence point result in partially ordered metric spaces for compatible mappings," Nonlinear Analysis: Theory, Methods \& Applications, vol. 73, no. 8, pp. 2524-2531, 2010.

[10] B. S. Choudhury and P. Maity, "Coupled fixed point results in generalized metric spaces," Mathematical and Computer Modelling, vol. 54, no. 1-2, pp. 73-79, 2011.

[11] L. Ćirić, B. Damjanović, M. Jleli, and B. Samet, "Coupled fixed point theorems for generalized Mizoguchi-Takahashi contractions with applications," Fixed Point Theory and Applications, vol. 2012, article 51, 2012.

[12] H.-S. Ding, L. Li, and S. Radenović, "Coupled coincidence point theorems for generalized nonlinear contraction in partially ordered metric spaces," Fixed Point Theory and Applications, vol. 2012, article 96, 2012.

[13] D. J. Guo and V. Lakshmikantham, "Coupled fixed points of nonlinear operators with applications," Nonlinear Analysis: Theory, Methods \& Applications, vol. 11, no. 5, pp. 623-632, 1987.

[14] N. Hussain, M. Abbas, A. Azam, and J. Ahmad, "Coupled coincidence point results for a generalized compatible pair with applications," Fixed Point Theory and Applications, vol. 2014, article 62, 2014.

[15] N. Hussain, P. Salimi, and S. al-Mezel, "Coupled fixed point results on quasi-Banach spaces with application to a system of integral equations," Fixed Point Theory and Applications, vol. 2013, article 261, 2013.

[16] N. Hussain, A. Latif, and M. H. Shah, "Coupled and tripled coincidence point results without compatibility," Fixed Point Theory and Applications, vol. 2012, article 77, 2012.

[17] V. Lakshmikantham and L. Ćirić, "Coupled fixed point theorems for nonlinear contractions in partially ordered metric spaces," Nonlinear Analysis: Theory, Methods \& Applications, vol. 70, no. 12, pp. 4341-4349, 2009.

[18] N. V. Luong and N. X. Thuan, "Coupled fixed points in partially ordered metric spaces and application," Nonlinear Analysis: Theory, Methods \& Applications, vol. 74, no. 3, pp. 983-992, 2011.

[19] J. J. Nieto and R. Rodríguez-López, "Existence and uniqueness of fixed point in partially ordered sets and applications to ordinary differential equations," Acta Mathematica Sinica, vol. 23, no. 12, pp. 2205-2212, 2007.

[20] A. C. M. Ran and M. C. B. Reurings, "A fixed point theorem in partially ordered sets and some applications to matrix equations," Proceedings of the American Mathematical Society, vol. 132, no. 5, pp. 1435-1443, 2004.

[21] J. R. Roshan, V. Parvaneh, and I. Altun, "Some coincidence point results in ordered $b$-metric spaces and applications in a system of integral equations," Applied Mathematics and Computation, vol. 226, pp. 725-737, 2014.

[22] J. R. Roshan, V. Parvaneh, S. Sedghi, N. Shobkolaei, and W. Shatanawi, "Common fixed points of almost generalized $(\psi, \varphi)_{s}$-contractive mappings in ordered $b$-metric spaces," Fixed Point Theory and Applications, vol. 2013, article 159, 2013.

[23] M. Mursaleen, S. A. Mohiuddine, and R. P. Agarwal, "Coupled fixed point theorems for $\alpha-\psi$-contractive type mappings in partially ordered metric spaces," Fixed Point Theory and Applications, vol. 2012, article 228, 2012.

[24] V. Parvaneh, J. R. Roshan, and S. Radenović, "Existence of tripled coincidence points in ordered $b$-metric spaces and an application to a system of integral equations," Fixed Point Theory and Applications, vol. 2013, article 130, 2013.

[25] V. Berinde and M. Borcut, "Tripled fixed point theorems for contractive type mappings in partially ordered metric spaces," Nonlinear Analysis: Theory, Methods \& Applications, vol. 74, no. 15, pp. 4889-4897, 2011.

[26] M. Borcut, "Tripled coincidence theorems for contractive type mappings in partially ordered metric spaces," Applied Mathematics and Computation, vol. 218, no. 14, pp. 7339-7346, 2012.

[27] M. Borcut and V. Berinde, "Tripled coincidence theorems for contractive type mappings in partially ordered metric spaces," Applied Mathematics and Computation, vol. 218, no. 10, pp. 5929-5936, 2012.

[28] B. S. Choudhury, E. Karapınar, and A. Kundu, "Tripled coincidence point theorems for nonlinear contractions in partially ordered metric spaces," International Journal of Mathematics and Mathematical Sciences, vol. 2012, Article ID 329298, 14 pages, 2012.

[29] Y. J. Cho, B. E. Rhoades, R. Saadati, B. Samet, and W. Shatanawi, "Nonlinear coupled fixed point theorems in ordered generalized metric spaces with integral type," Fixed Point Theory and Applications, vol. 2012, article 8, 2012. 
[30] H. Aydi, E. Karapınar, and W. Shatanawi, “Tripled coincidence point results for generalized contractions in ordered generalized metric spaces," Fixed Point Theory and Applications, vol. 2012, article 101, 2012.

[31] B. Samet, C. Vetro, and P. Vetro, "Fixed point theorems for $\alpha-\psi$-contractive type mappings," Nonlinear Analysis: Theory, Methods \& Applications, vol. 75, no. 4, pp. 2154-2165, 2012.

[32] M. A. Alghamdi and E. Karapınar, " $G-\beta-\psi$ contractive-type mappings and related fixed point theorems," Journal of Inequalities and Applications, vol. 2013, article 70, 2013.

[33] N. Hussain, S. al-Mezel, and P. Salimi, "Fixed points for $\psi$ graphic contractions with application to integral equations," Abstract and Applied Analysis, vol. 2013, Article ID 575869, 11 pages, 2013.

[34] E. Karapınar, P. Kumam, and P. Salimi, "On $\alpha-\psi$-Meir-Keeler contractive mappings," Fixed Point Theory and Applications, vol. 2013, article 94, 2013.

[35] N. Hussain, E. Karapınar, P. Salimi, and P. Vetro, "Fixed point results for $G^{m}$-Meir-Keeler contractive and $G-(\alpha, \psi)$ Meir-Keeler contractive mappings," Fixed Point Theory and Applications, vol. 2013, article 34, 2013.

[36] Z. Mustafa, J. R. Roshan, and V. Parvaneh, "Existence of tripled coincidence point in ordered $G_{b}$-metric spaces and applications to a system of integral equations," Journal of Inequalities and Applications, vol. 2013, article 453, 2013.

[37] V. Berinde, "Coupled fixed point theorems for $\phi$-contractive mixed monotone mappings in partially ordered metric spaces," Nonlinear Analysis: Theory, Methods \& Applications, vol. 75, no. 6, pp. 3218-3228, 2012.

[38] N. V. Luong and N. X. Thuan, "Coupled fixed point theorems in partially ordered G-metric spaces," Mathematical and Computer Modelling, vol. 55, no. 3-4, pp. 1601-1609, 2012. 


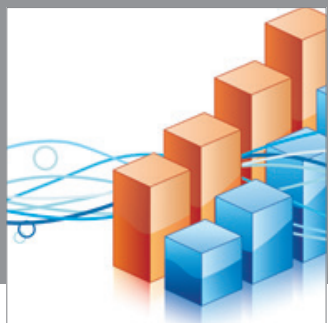

Advances in

Operations Research

mansans

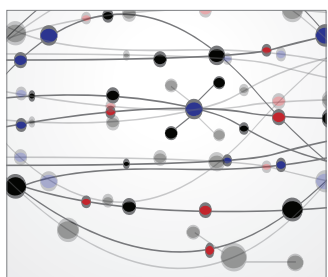

The Scientific World Journal
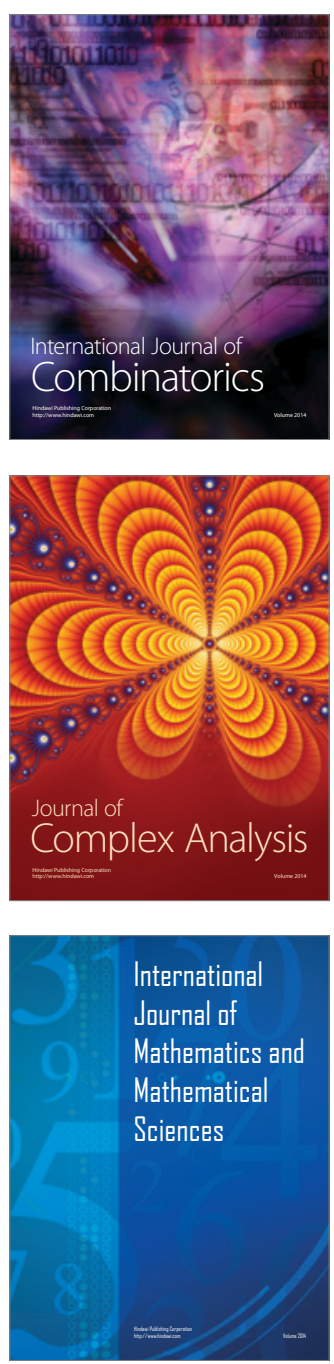
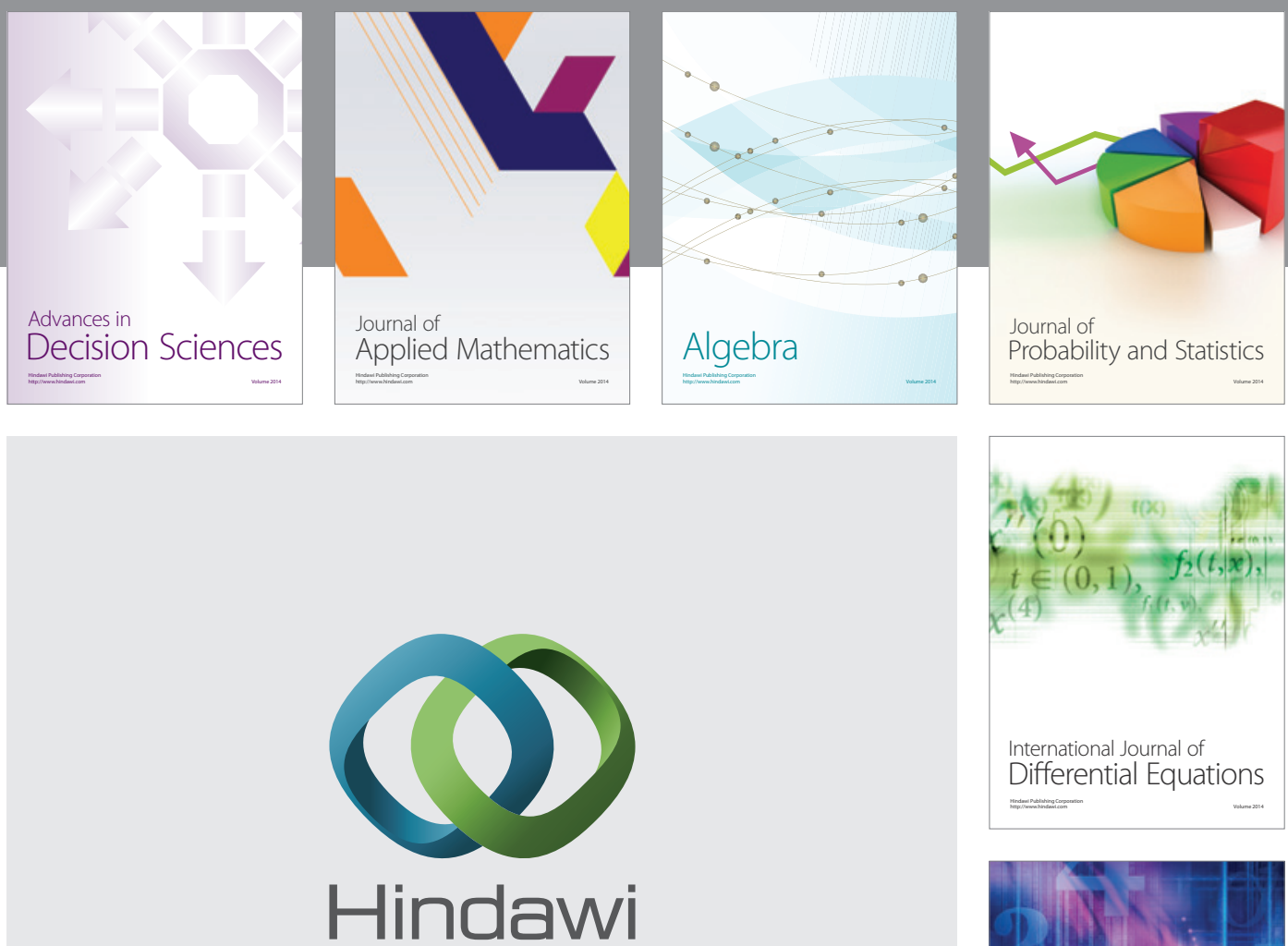

Submit your manuscripts at http://www.hindawi.com
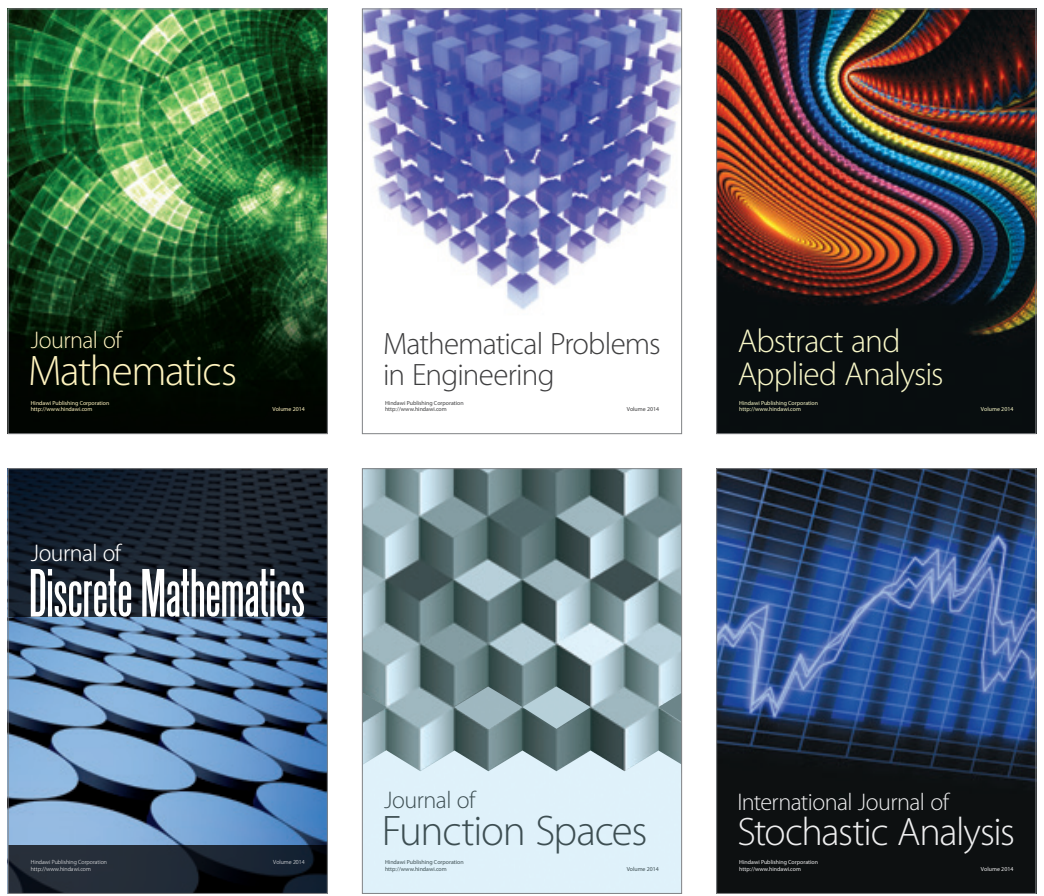

Journal of

Function Spaces

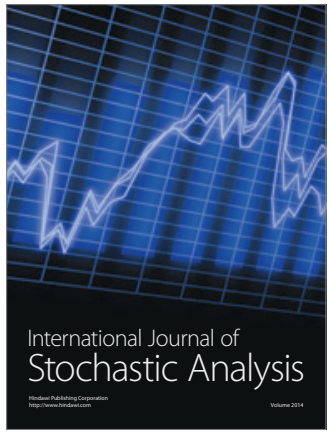

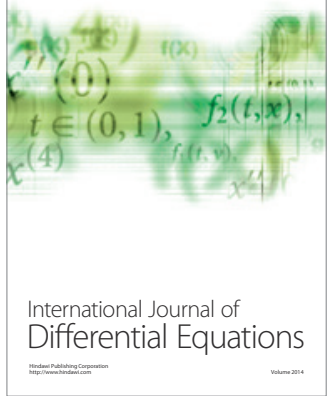
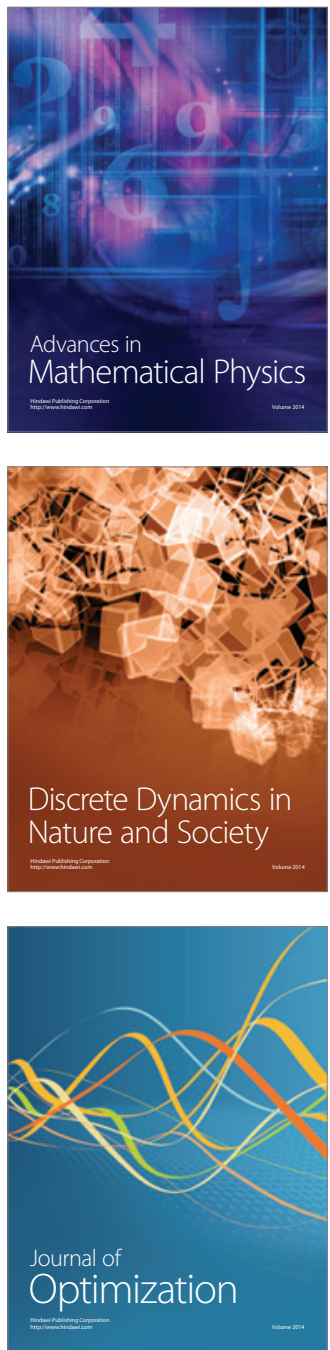